\title{
The Scenario Model Intercomparison Project (ScenarioMIP) for CMIP6
}

Brian C. O'Neill ${ }^{1}$, Claudia Tebaldi ${ }^{1}$, Detlef P. van Vuuren ${ }^{2,3}$, Veronika Eyring ${ }^{4}$, Pierre Friedlingstein ${ }^{5}$, George Hurtt ${ }^{6}$, Reto Knutti $^{7}$, Elmar Kriegler ${ }^{8}$, Jean-Francois Lamarque ${ }^{1}$, Jason Lowe ${ }^{9}$, Gerald A. Meehl ${ }^{1}$, Richard Moss ${ }^{10}$, Keywan Riahi ${ }^{11,12}$, and Benjamin M. Sanderson ${ }^{1}$

${ }^{1}$ National Center for Atmospheric Research (NCAR), Boulder, CO 80305, USA

${ }^{2}$ Netherlands Environmental Assessment Agency (PBL), The Hague, the Netherlands

${ }^{3}$ Copernicus Institute for Sustainable Development, Utrecht University, Utrecht, the Netherlands

${ }^{4}$ Deutsches Zentrum für Luft- und Raumfahrt (DLR), Institut für Physik der Atmosphäre, Oberpfaffenhofen, Germany

${ }^{5}$ University of Exeter, Exeter, UK

${ }^{6}$ University of Maryland, College Park, MD, USA

${ }^{7}$ Institute for Atmospheric and Climate Science, ETH Zurich, 8092 Zurich, Switzerland

${ }^{8}$ Potsdam Institute for Climate Impact Research (PIK), Potsdam, Germany

${ }^{9}$ Met Office Hadley Centre, Exeter, UK

${ }^{10}$ Pacific Northwest National Laboratory's Joint Global Change Research Institute at the University of Maryland, College Park, MD, USA

${ }^{11}$ International Institute for Applied Systems Analysis (IIASA), Laxenburg, Austria

${ }^{12}$ Graz University of Technology, Graz, Austria

Correspondence to: Brian C. O’Neill (boneill@ucar.edu)

Received: 8 April 2016 - Published in Geosci. Model Dev. Discuss.: 22 April 2016

Revised: 16 August 2016 - Accepted: 31 August 2016 - Published: 28 September 2016

\begin{abstract}
Projections of future climate change play a fundamental role in improving understanding of the climate system as well as characterizing societal risks and response options. The Scenario Model Intercomparison Project (ScenarioMIP) is the primary activity within Phase 6 of the Coupled Model Intercomparison Project (CMIP6) that will provide multi-model climate projections based on alternative scenarios of future emissions and land use changes produced with integrated assessment models. In this paper, we describe ScenarioMIP's objectives, experimental design, and its relation to other activities within CMIP6. The ScenarioMIP design is one component of a larger scenario process that aims to facilitate a wide range of integrated studies across the climate science, integrated assessment modeling, and impacts, adaptation, and vulnerability communities, and will form an important part of the evidence base in the forthcoming Intergovernmental Panel on Climate Change (IPCC) assessments. At the same time, it will provide the basis for investigating a number of targeted science and policy questions that are
\end{abstract}

especially relevant to scenario-based analysis, including the role of specific forcings such as land use and aerosols, the effect of a peak and decline in forcing, the consequences of scenarios that limit warming to below $2{ }^{\circ} \mathrm{C}$, the relative contributions to uncertainty from scenarios, climate models, and internal variability, and long-term climate system outcomes beyond the 21 st century. To serve this wide range of scientific communities and address these questions, a design has been identified consisting of eight alternative 21st century scenarios plus one large initial condition ensemble and a set of long-term extensions, divided into two tiers defined by relative priority. Some of these scenarios will also provide a basis for variants planned to be run in other CMIP6Endorsed MIPs to investigate questions related to specific forcings. Harmonized, spatially explicit emissions and land use scenarios generated with integrated assessment models will be provided to participating climate modeling groups by late 2016, with the climate model simulations run within the 2017-2018 time frame, and output from the climate model 
projections made available and analyses performed over the 2018-2020 period.

\section{Introduction}

Scenarios describing possible future developments of anthropogenic drivers of climate change (i.e., greenhouse gases, chemically reactive gases, aerosols, and land use) consistent with socioeconomic developments play an important role in climate research. They allow an assessment of possible changes in the climate system, impacts on society and ecosystems, and the effectiveness of response options such as adaptation and mitigation under a wide range of future outcomes.

Scenarios produced in the Intergovernmental Panel on Climate Change (IPCC) Special Report on Emissions Scenarios (SRES; Nakicénović et al., 2000) formed the basis for climate model projections in Phase 3 of the Coupled Model Intercomparison Project (CMIP3; Meehl et al., 2007) and their assessment in the IPCC AR4 Working Group I (IPCC, 2007a), and were used to model impacts on society and ecosystems (IPCC, 2007, 2014a, b) and mitigation strategies (IPCC, 2001b, 2007c, 2014c). In 2007, an expert meeting at Noordwijkerhout agreed on a process for the development of new community scenarios (Moss et al., 2008, 2010). That process began with the identification of the Representative Concentration Pathways (RCPs; van Vuuren et al., 2011a), a set of four pathways of land use and emissions of air pollutants and greenhouse gases that spanned a wide range of future outcomes through 2100. The RCPs were the basis for climate model projections in CMIP5 (Taylor et al., 2012) and their assessment in the IPCC AR5 (IPCC, 2013).

The Scenario Model Intercomparison Project (ScenarioMIP) is now the primary activity within CMIP6 that will provide multi-model climate projections based on alternative scenarios that are directly relevant to societal concerns regarding climate change mitigation, adaptation, or impacts. These climate projections will be driven by a new set of emissions and land use scenarios (Riahi et al., 2016) produced with integrated assessment models (IAMs) based on new future pathways of societal development, the Shared Socioeconomic Pathways (SSPs), and related to the RCPs. CMIP6 climate projections will differ from those in CMIP5 not only because they are produced with updated versions of climate models, but also because they are driven with SSP-based scenarios produced with updated versions of IAMs and based on updated data on recent emissions trends. Unlike in CMIP3 and CMIP5, where climate model projections were part of the core experiments, in CMIP6 they are part of a dedicated CMIP6-Endorsed MIP (Eyring et al., 2016).

In Sect. 2, we describe the process by which ScenarioMIP's experimental design was formulated and its objectives. This includes its role in providing an integrating research framework across communities and in addressing spe- cific research and policy questions. We provide background on the broader scenario process in which ScenarioMIP simulations will play a role and identify the specific scientific questions it aims to address. Section 3 then describes the experimental design, summarizing the types of model experiments to be run by the CMIP6 climate model groups separated into two tiers differentiated by priority, as well as the relation of the design to other components of CMIP6. Section 4 describes the planned inputs to climate models to be provided by integrated assessment models developing the emissions and land use scenarios, as well as the climate model outputs to be analyzed and made available to the community. Section 5 provides a concluding discussion.

\section{ScenarioMIP process, objectives, and background}

\subsection{ScenarioMIP process}

Because of the importance of the ScenarioMIP simulations across multiple research fields and to policy makers, the experimental design was developed collaboratively by researchers within the climate science, IAM, and impacts, adaptation, and vulnerability (IAV) communities. The idea for an activity within CMIP6 focused on scenarios was elaborated in discussions in 2013 among the IAM, IAV and climate modeling communities. ${ }^{1}$ A ScenarioMIP Scientific Steering Committee (SSC) charged with proposing an experimental design was then formed following the 17th session of the World Climate Research Programme (WCRP) Working Group on Coupled Modeling (WGCM) in October 2013 in Victoria, Canada.

The ScenarioMIP SSC together with other communities (see below) systematically investigated a number of issues that could substantially influence the experimental design, especially those that would affect the required number of model runs. First, the possibility was considered to identify a smaller subset of scenarios to be run by statistically sampling from among the large number of possible combinations of different SSPs, forcing targets, IAMs, and climate models. It was decided that this approach could currently not be carried out with a reasonable number of climate model simulations without sacrificing the representation of uncertainty for a given scenario. Second, the potential for pattern scaling or other statistical emulators of climate model output to meet some of the demand for scenario-based climate information was considered. A workshop held for this purpose concluded that pattern scaling has currently not yet been demonstrated to be able to reli-

\footnotetext{
${ }^{1}$ Key discussions occurred at the annual meeting of the integrated assessment and impacts communities in Snowmass, CO, in July 2013, and a meeting on CMIP6 at the Aspen Global Change Institute in Aspen, CO, in August 2013, Next Generation Climate Change Experiments Needed to Advance Knowledge and for Assessment of CMIP6 (Meehl et al., 2014).
} 
ably replace the need for climate model projections to generate information for impact studies (although it might play a role for some applications, e.g. Tebaldi and Arblaster, 2014; see workshop report at https://www2.image.ucar.edu/ sites/default/files/event/PS2014WorkshopReport_0.pdf). Finally, the difference between scenarios (in terms of global average forcing or temperature change) that is required to produce significantly different climate outcomes was investigated. Initial studies indicate that scenario differences of at least $0.3^{\circ} \mathrm{C}$ in global average surface temperature are likely necessary to generate statistically significant differences in local temperature over a substantial fraction of the surface, and substantially larger differences are required to produce similarly significant and extensive differences in precipitation outcomes (Tebaldi et al., 2015). Further work on this topic is desirable, especially to explore the sensitivity of additional impact-relevant variables, time and spatial scales of interest, and local forcings.

Informed by these conclusions, a process was organized by the SSC to develop a final protocol. This process included close interaction with the climate research, IAMs and IAV communities through presentations and discussions at a number of meetings in 2014 and $2015,^{2}$ as well as coordination with other MIPs developing proposals for CMIP6. It also involved discussions with representatives of the Integrated Assessment Modeling Consortium's (IAMC's) Working Group on Scenarios, which is coordinating the production of SSP-based energy-land use-emissions scenarios (Riahi et al., 2016) for CMIP6, and discussions with key individuals in other relevant research communities, including through the International Committee On New Integrated Climate change assessment Scenarios (ICONICS). Feedback on various drafts was also received from the CMIP review process and from relevant groups including ICONICS, the IPCC Task Group on Data and Scenario Support for Impacts and Climate Analysis (TGICA), the CMIP panel, and the WCRP Working Group on Regional Climate.

\subsection{ScenarioMIP objectives}

ScenarioMIP has three primary objectives:

a. Facilitate integrated research leading to a better understanding not only of the physical climate system consequences of these scenarios, but also of the climate impact on societies. The results of the ScenarioMIP experiments will provide new climate information for

\footnotetext{
${ }^{2}$ Session at the July 2014 Snowmass meeting on integrated assessment and impacts; joint meeting on proposed CMIP6 MIPs on scenarios, land use, and aerosols and chemistry, Aspen Global Change Institute, August 2014 (O'Neill et al., 2014a); WCRP-IPCC WG1 meeting in Bern, Switzerland, September 2014; WGCM18 meeting in October 2014; annual meeting of the Integrated Assessment Modeling Consortium, November 2014; IPCC expert meeting on scenarios, IIASA, Laxenburg, Austria, May 2015.
}

future scenarios that will facilitate integrated research across multiple communities including the (1) climate science, (2) integrated assessment modeling, and (3) impacts, adaptation, and vulnerability communities. This research will be key in informing mitigation and adaptation policy considerations, including processes that are part of the UN Framework Convention on Climate Change (UNFCCC) such as the 2015 Paris Climate Agreement.

b. Provide a basis for addressing targeted science questions in ScenarioMIP and other CMIP6 projects, regarding the climate effects of particular aspects of forcing relevant to scenario-based research. This includes the effects of a substantial overshoot in radiative forcing and the effect of different assumptions on land use and near-term climate forcers (NTCFs; namely tropospheric aerosols, tropospheric $\mathrm{O}_{3}$ precursors, and $\mathrm{CH}_{4}$ ) on climate change and its impacts. Therefore, a set of variants of the scenarios proposed here are being proposed in other CMIP6-Endorsed MIPs (see Sect. 2.3.3) to address targeted questions.

c. Provide a basis for research efforts that target improved methods to quantify projection uncertainties based on multi-model ensembles, taking into account model performance, model dependence and observational uncertainty. This extends the knowledge basis derived from the Diagnostic, Evaluation and Characterization of Klima (DECK) experiments and the CMIP6 historical simulations (Eyring et al., 2016) and allows for the quantification of uncertainties on different timescales. ScenarioMIP will provide some of the results needed in the next IPCC assessment to characterize the uncertainty in future climate and impacts.

The first objective is considered to be the highest priority for several reasons. First, "scenarios for integration" serve a large scientific audience, underpinning hundreds of scenariobased studies addressing a wide variety of scientific questions regarding physical climate changes, mitigation, impacts, and adaptation. Having common climate and socioeconomic scenarios serves as a critical means to enhance direct comparability of a wide variety of studies, allowing synthetic conclusions to be drawn that would not be possible from a variety of uncoordinated studies (van Vuuren et al., 2012; Kriegler et al., 2012). The climate simulations produced by ScenarioMIP will constitute a key element of a larger, coordinated process within the climate change research community to produce both socioeconomic and climate scenarios that can underpin integrated research for many years to come (Sect. 2.3).

Second, scenarios for integration can serve as a key means for producing better integrated scientific assessments, such as those connecting different working groups and the synthesis report of IPCC. 
Third, the recent Paris Agreement adopted by parties to the UNFCCC (2015) has focused renewed attention on the goal of limiting warming to below $2{ }^{\circ} \mathrm{C}$ global mean temperature change relative to pre-industrial and encouraged countries to pursue efforts to limit warming to an even lower goal of $1.5^{\circ} \mathrm{C}$. Integrated scenarios can help inform dialogues and associated comparative climate changes to help address these political goals.

Finally, a common set of scenarios for integration reduces the need for individual research projects to develop their own scenario information to support scenario-based studies. The availability of common scenarios reduces possible redundancy in efforts and makes scenario-based research feasible for many groups that otherwise would not be able to carry it out.

\subsection{The scenario framework}

Moss et al. (2010) introduced a parallel approach for developing new community scenarios, followed by an integration phase. One of the parallel tracks was the production of climate model projections based on the four RCPs as part of CMIP5 (Taylor et al., 2012). The other track developed alternative future societal development pathways (the SSPs) and emissions and land use scenarios based on them, generated with IAMs. The integration phase brings together the climate simulations and SSP-based societal futures to carry out integrated analysis.

The SSPs were developed over the last several years as a community effort and describe global developments leading to different challenges for mitigation and adaptation to climate change. A conceptual framework for the SSPs and how they could be used with RCP-based climate simulations to carry out integrated research was developed first (van Vuuren et al., 2012, 2014; O'Neill et al., 2014b; Kriegler et al., 2012, 2014a). The specific content of the SSPs was developed next (Riahi et al, 2016). These comprise five alternative narratives that describe the main characteristics of the pathways in qualitative terms (O'Neill et al., 2015) as well as quantitative descriptions for key elements including population (KC and Lutz, 2014), economic growth (Dellink et al., 2015), and urbanization (Jiang and O'Neill, 2015).

In short, the SSPs describe alternative evolutions of future society in the absence of climate change or climate policy. SSPs 1 and 5 envision relatively optimistic trends for human development, with substantial investments in education and health, rapid economic growth, and well-functioning institutions. However, SSP5 assumes an energy intensive, fossilbased economy, while in SSP1 there is an increasing shift toward sustainable practices. SSPs 3 and 4 envision more pessimistic development trends, with little investment in education or health, fast growing population, and increasing inequalities. In SSP3 countries prioritize regional security, whereas in SSP4 large inequalities within and across countries dominate, in both cases leading to societies that are highly vulnerable to climate change. SSP2 envisions a central pathway in which trends continue their historical patterns without substantial deviations.

IAM scenarios were then developed based on the SSPs by elaborating on their implications for energy systems (Bauer et al., 2016) and land use changes (Popp et al., 2016) and quantifying resulting greenhouse gas emissions and atmospheric concentrations (Riahi et al., 2016). These SSP-based IAM scenarios consist of a set of baseline scenarios, which provide a description of future developments in the absence of climate change impacts or new climate policies beyond those in place today, as well as mitigation scenarios which explore the implications of climate change mitigation policies applied to the baseline scenarios. Multiple IAMs were used for the quantification of the SSP scenarios, and a single "marker" scenario was selected as representative in each case. Scenarios in the ScenarioMIP design are selected from these marker scenarios.

Integrated analyses drawing on the qualitative and quantitative elements of the SSPs and climate change information from the CMIP5 simulations of the RCPs have already begun to appear (e.g., Alfieri et al., 2015; Arnell et al., 2014; Biewald et al., 2015; Dong et al., 2015; Hejazi et al., 2015) and climate model simulations with the RCPs will continue to be a key input to research on climate change and impacts for many years. ScenarioMIP is playing a key role by identifying an updated and expanded set of concentration pathways based on the SSPs to be run by climate models as part of CMIP6. These CMIP6 simulations will allow integrated analyses to be carried out using climate simulations based on the latest versions of climate models, for a larger set of concentration pathways based on the most recent versions of IAMs.

Figure 1 visualizes how SSPs can be combined with climate simulations from either CMIP5 or CMIP6, using the example of a forcing pathway stabilizing at $4.5 \mathrm{~W} \mathrm{~m}^{-2}$. In general, each SSP forcing pathway combination represents an integrated scenario of future climate and societal change which would be used to investigate issues such as the mitigation effort required to achieve that particular climate outcome, the possibilities for adaptation under that climate outcome and assumed societal conditions, and the remaining impacts on society or ecosystems. The full set of multiple SSPs and forcing outcomes forms a matrix of possible integrated scenarios (van Vuuren et al., 2012, 2014; Kriegler et al., 2012). Each row contains climate model simulations based on a forcing pathway (e.g., a $4.5 \mathrm{~W} \mathrm{~m}^{-2}$ pathway in Fig. 1), which can be used in combination with the societal conditions described by any of the SSPs, as long as it is feasible that SSP emissions could be made consistent with that forcing pathway (see Sect. 3.1.1 for a discussion of feasibility). We refer to these scenarios as $\operatorname{SSP} x-y$, where $x$ is the specific SSP and $y$ represents the forcing pathway, defined 


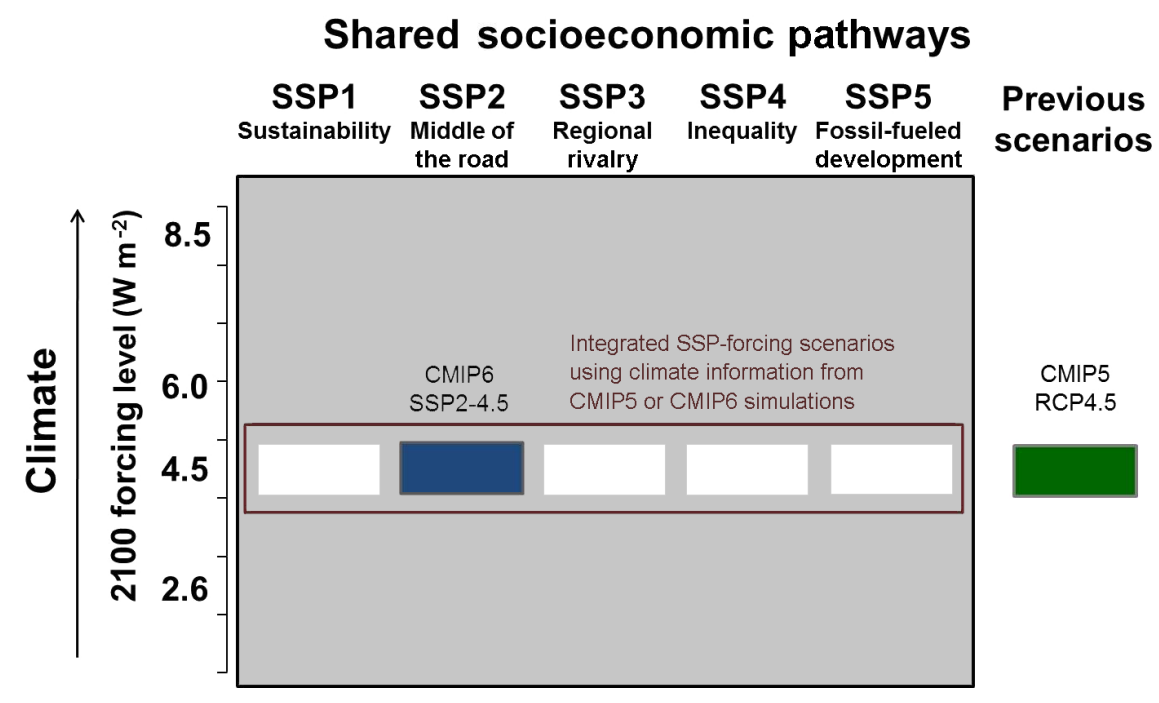

Figure 1. SSP forcing scenario matrix illustrating the combination of a $4.5 \mathrm{~W} \mathrm{~m}^{-2}$ forcing pathway with alternative SSPs. The dark blue cell illustrates a scenario serving as part of the design of ScenarioMIP. The green cell represents RCP4.5 in CMIP5, which was based on a previous emissions and land use scenario. White cells indicate scenarios for which climate information would come from either the CMIP5 or CMIP6 simulations.

by its long-term global average radiative forcing level. ${ }^{3}$ In the example shown in the figure, mitigation policies would be added to each SSP to produce a forcing pathway that stabilized at $4.5 \mathrm{~W} \mathrm{~m}^{-2}$, and SSP2-4.5 is singled out as the specific scenario that would be used as input to climate model simulations in ScenarioMIP.

Currently, RCP simulations from CMIP5 are available to provide climate information for integrated scenarios combining SSP-based socioeconomic and energy-emissions-land use scenarios (as, e.g., SSP2-4.5) with the climate change projections from CMIP5 (e.g., the RCP4.5 simulations). CMIP5 RCPs were derived from earlier emissions and land use scenarios (van Vuuren et al., 2011b), and therefore the regional pattern of climate change resulting from an RCP climate simulation would not be identical with an SSP $x-y$ simulation following a similar global forcing pathway. An enabling hypothesis of the parallel process is that differences in climate change projections would be small enough to still warrant integration of the two sets of information into mitigation, impacts and adaptation analysis. The ScenarioMIP design will include an updated and expanded set of forcing pathways directly derived from SSPs. Once they become available, climate model simulations based on these pathways will then be used to provide climate information for integrated studies.

\footnotetext{
${ }^{3}$ Following practice established for the RCPs, the forcing level usually refers to the forcing achieved in 2100 but in some cases refers to an intended forcing stabilization level that is reached beyond 2100. Forcing is reported as global average radiative forcing, not effective radiative forcing (Myhre et al., 2013).
}

\subsection{Scientific questions addressed by ScenarioMIP}

As noted in Sect. 2.2, the highest priority objective for ScenarioMIP is to provide climate model simulations that can facilitate a wide range of integrated research on the climate impact on societies, including considerations of mitigation and adaptation. Thus, an overarching interdisciplinary science question addressed by ScenarioMIP simulations is

What are the mitigation efforts, climate outcomes, impacts, and adaptation options that would be associated with a range of radiative forcing pathways?

However in addition, ScenarioMIP simulations will be key to addressing two of the three CMIP6 science questions that have informed the overall CMIP6 design and the endorsement of proposed MIPs, related to the effects of external forcings on the Earth system and to the confounding effects of different sources of uncertainty on future anthropogenic climate change outcomes. Table 1 lists the two questions along with a number of sub-questions that ScenarioMIP experiments are intended to explore. In addition, studies addressing WCRP Grand Challenges (clouds, circulation and climate sensitivity, melting ice and global consequences, climate extremes, regional sea-level change and coastal impacts and water availability) will benefit from the availability of outcomes from future scenario simulations.

The scenario framework described in Sect. 2.3 raises specific questions that ScenarioMIP, in collaboration with other CMIP6-Endorsed MIPs (in particular, the Land Use MIP (LUMIP) and Aerosols and Chemistry MIP (AerChemMIP)) will also help address through coordinated experiments in 
Table 1. Scientific questions addressed by ScenarioMIP related to the CMIP6 science questions.

\begin{tabular}{ll}
\hline CMIP6 science question & Sub-questions addressed by ScenarioMIP \\
\hline - How does the Earth system & - How does the Earth system respond to forcing pathways relevant to IAM and IAV research \\
respond to forcing? & and to policy considerations? \\
- What is the uncertainty in global and regional climate change due to variations in future land \\
use and NTCFs emissions that are feasible in an IAM, and how does it compare to multi-model \\
uncertainty in the response to a given forcing pathway? \\
How much do alternative shapes of forcing pathways (e.g. overshoot) feasible to produce in an \\
IAM matter to climate change outcomes, and therefore to questions about mitigation, impacts, \\
and adaptation? \\
- What is the uncertainty in global and regional climate as a result of model uncertainty (as \\
opposed to scenario variations), and how can this be estimated from a model ensemble of op- \\
portunity without a specific design to sample uncertainty? \\
Can emergent constraints (i.e., statistical relationships between features of current and pro- \\
jected future climate that emerge from considering the multi-model ensemble as a whole) be \\
used to recalibrate the ensemble and to quantify or reduce the uncertainty in the response to a \\
given scenario of future forcing? \\
- In which part of the Earth system, and when, are such constraints expected to emerge, how do \\
they trace back to modeled processes, are those processes adequately represented, and how can \\
this information be used to improve models, point to critical observations and monitoring pro- \\
grams, and link process understanding, detection and attribution, projections, and uncertainty \\
quantification?
\end{tabular}

- How can we assess future climate changes given climate variability, climate predictability, and uncertainties in scenarios?
- How can we assess future climate changes for forcing pathways spanning a range of uncertainties in global and regional forcing relevant to IAM and IAV research, as well as to policy? which variants of ScenarioMIP scenarios will be run by other MIPs.

Are differences in regional forcing, or forcings not included in definition of targets (e.g., biophysical effects), a source of significant differences in climate outcomes across a matrix row?

The rows of the SSP forcing matrix shown in Fig. 1 are defined by forcing pathways that achieve the same level of global average radiative forcing in 2100 . ScenarioMIP will carry out climate model simulations for one particular land use and concentration pathway that leads to this level of radiative forcing. However, in principle this forcing level can be achieved via pathways of emissions and land use that differ widely in terms of regional land use patterns, regional patterns of emissions of NTCFs, and mixes of global emissions of greenhouse gases (GHGs) and NTCFs. For example, the different SSPs making up a given row of the matrix will have different patterns of regional economic growth, energy system development, air quality policies, land use, and other characteristics that will lead to the same global average forcing outcome being achieved by different means in each case. Thus, an open scientific question is the degree to which climate outcomes can be expected to differ between land use and emissions pathways that achieve the same global aver- age radiative forcing level in 2100 but have different patterns of regional forcing.

An assumption underlying the parallel process (Moss et al., 2010) and the SSP scenario framework is that these differences in climate outcomes are likely to be small relative to the overall uncertainty in applications of these simulations to integrated analyses (including impact assessments). This assumption is critical to be able to combine a ScenarioMIP climate simulation for a given SSP and forcing level with scenarios based on other SSPs achieving the same forcing level. Experiments carried out in other MIPs based on scenarios in the ScenarioMIP design will help test this assumption (see Sect. 3.3.3). If it turns out that climate outcomes are much more sensitive to local forcing differences than currently assumed, the ability to use ScenarioMIP simulations for each forcing level for all SSPs might not be possible for all studies. In that case, Earth system model (ESM) simulations specific to each combination of SSP and forcing pathway would be required.

In addition, the definition of global average forcing in 2100 includes the forcing effect of GHGs and NTCFs, but excludes the biophysical effects of land use change on climate (e.g., through albedo or changes to the hydrological cycle). Thus, it is also an open question whether alternative pathways that achieve the same level of global average radiative forcing as defined here, but differ in forcing due to 
the biophysical effects of land use change, would produce substantially different climate outcomes.

What are global and regional climate differences between scenarios with small differences in forcing levels?

The experimental design includes six out of eight $21 \mathrm{st}$ century scenarios that are within a maximum of $1.0 \mathrm{~W} \mathrm{~m}^{-2}$ of another scenario in terms of global average radiative forcing in 2100. Early in the design of the scenario framework, a criterion for selecting RCPs was that they be well separated in terms of radiative forcing (Moss et al., 2008). More recent work (Tebaldi et al., 2015) has refined this view, indicating that regional temperature outcomes that are statistically significantly different at a $5 \%$ level for more than half the land surface area, and robustly so across the multi-model ensemble, require a separation of at least $0.3^{\circ} \mathrm{C}$ in global average temperature. This difference in global temperature is roughly equivalent to about $0.75 \mathrm{~W} \mathrm{~m}^{-2}$ of global average forcing in an idealized $1 \% \mathrm{yr}^{-1} \mathrm{CO}_{2}$ increase experiment, although the equivalent value is sensitive to the forcing pathway. For regional precipitation, a much wider separation is required to ensure that scenarios are statistically different. From a policy-making perspective the issue of scenario separation is also important, as policy interest often focuses on the differential impacts between climate change or forcing levels that are relatively close to each other. The ScenarioMIP design will allow for further analysis of these types of questions, providing simulations that will allow addressing region- and variable-specific sensitivities, dependence on geographic and temporal scale of variable differences, and the role of internal variability.

What are the effects of declines in forcing (overshoot scenarios)?

There is both scientific and policy interest in the climate outcomes associated with forcing pathways that exceed a given forcing level and later peak and decline back to that level (overshoot pathways). Such pathways may become increasingly a point of discussion if there is a persistent gap between moderate near-term emission reduction efforts and the ambition to limit climate forcing and global mean warming to very low levels. To this end, the lowest RCP (RCP2.6), and the low SSP scenarios, already exhibit a limited degree of concentration overshoot. One of the scenarios within the ScenarioMIP design describes a much stronger overshoot pathway with radiative forcing that peaks and declines within the 21 st century and declines further thereafter, allowing for investigation of the effect of overshoot and declining forcing on the climate system and society. In particular, it allows investigating to what extent climate impacts are higher and what long-lasting and potentially irreversible changes in the climate system occur in an overshoot scenario.
Can pattern scaling, or other approaches to climate model emulation, be used to produce climate outcomes for forcing pathways not represented in the ScenarioMIP design?

Climate model emulators have the potential to provide a computationally efficient means of generating climate outcomes for arbitrary scenarios and, in so doing, facilitate the representation of uncertainty in applications to impact studies (Tebaldi and Arblaster, 2014). However, the state of development of such emulators is such that many situations remain where they are not suitable, their behavior deviating significantly from the more computationally complex, physically based models that they seek to emulate, or falling short of producing temporally coherent projections, or projections of multiple variables physically inter-related. A more systematic exploration and development of such techniques in order to realize their potential will be facilitated by the availability of ScenarioMIP simulations, according to a design that deliberately explores a large range of forcings (both with respect to a lower and upper end, recently found to be important in training emulators by Herger et al., 2015), non-traditional pathways like substantial overshoots and long-term extensions and, together with collaborating MIPs, the effects of regionally and time-varying forcers other than well-mixed, long-lived GHGs, in particular land use changes and NTCFs.

Can emergent constraints (i.e., statistical relationships between features of current and projected future climate that emerge from considering the multi-model ensemble as a whole) be used to recalibrate the ensemble and to reduce the uncertainty in the response to a given scenario of future forcing?

A longstanding open scientific question is the relation between present-day model performance and future projections. A method to relate observed aspects of the present-day mean climate or recent trends to the Earth system response in some quantity is the so-called Emergent Constraints method (Allen and Ingram, 2002; Bracegirdle and Stephenson, 2013; Hall and Qu, 2006). An emergent constraint refers to the use of observations to constrain a simulated future Earth system feedback. It is referred to as emergent because a relationship between such a feedback and an observable element of climate variability emerges from an ensemble of ESM projections, providing a constraint on the future feedback. If physically plausible relationships can be found between, for example, changes occurring on seasonal or interannual timescales and changes found in anthropogenically-forced climate change, then models that simulate correctly the seasonal or interannual responses might make projections more reliably. For example, Hall and Qu (2006) found that large inter-model variations in the seasonal cycle of the albedo between April and May in the 20th century are well correlated with similarly large inter-model variations in the snow- 
albedo feedback on climatological timescales. The observable variation in the seasonal cycle of the snow albedo is then a useful proxy for constraining the unobservable feedback strength to climate warming, as both are driven by the same physical mechanisms on different timescales. Other examples include constraints on climate-carbon feedbacks (Cox et al., 2013; Wenzel et al., 2014), the Austral jet stream position (Wenzel et al., 2016), cloud feedbacks and equilibrium climate sensitivity (Huber et al., 2011; Fasullo and Trenberth, 2012; Fasullo et al., 2015; Klein and Hall, 2015; Knutti et al., 2006; Sherwood et al., 2014), and relations of past and future sea ice or temperature trends (Boé et al., 2009; Knutti and Tomassini, 2008; Mahlstein and Knutti, 2012; Massonet et al., 2012). The ScenarioMIP design will allow for testing emergent constraint results under various forcing pathways. The results will be valuable for guiding the design of future ensembles, e.g., how many and which models are needed to maximize information at minimal computational cost.

\section{Overview of ScenarioMIP experiment design}

The ScenarioMIP experimental design consists of a set of eight pathways of future emissions, concentrations and land use, with additional ensemble members and long-term extensions, grouped into two tiers of priority (of which only the first constitutes a required set for modeling centers participating in ScenarioMIP). We first discuss the rationale behind the types of pathways identified for inclusion in the design and then present a summary of the pathways constituting the design. Finally, we describe in more detail the features of the ScenarioMIP design and the specific scenarios on which it is based.

\subsection{Rationale for scenario selection}

The identification of the forcing pathways to be included in the ScenarioMIP design can be described in two parts: deciding on the forcing levels to include, and then on the specific SSP-based scenario that each forcing pathway should be based on. Additional decisions were then necessary on the number of ensemble members to request from each model for each scenario, and on long-term extensions beyond 2100 .

\subsubsection{Choosing forcing levels for CMIP6 scenarios}

Choices of the global average forcing level for scenarios to include in ScenarioMIP were based on the objectives outlined in Sect. 2.2. These objectives imply that the global average forcing pathways should cover a wide range of forcing levels, provide continuity with CMIP5 experiments, and fill in gaps in CMIP5 forcing pathways that would be of interest to the climate science, IAM, and IAV communities.
Based on these considerations, two types of pathways were included in the ScenarioMIP design:

1. Updated CMIP5 RCPs: new versions of the four RCPs used in CMIP5, based on the Shared Socioeconomic Pathways and new IAM simulations derived from them. This implies new, SSP-based versions of RCPs 2.6, 4.5, 6.0, and 8.5.

2. "Gap scenarios": new forcing pathways not covered by the RCPs, including new unmitigated SSP baseline scenarios and new mitigation pathways. Pathways identified of special interest, as discussed further below, were those reaching 7.0, 3.4, and below $2.6 \mathrm{~W} \mathrm{~m}^{-2}$ in 2100 (the latter explicitly to inform understanding of the $1.5^{\circ} \mathrm{C}$ goal in the Paris agreement). The $7.0 \mathrm{~W} \mathrm{~m}^{-2}$ pathway represents an unmitigated baseline scenario, whereas the 3.4 and $<2.6 \mathrm{~W} \mathrm{~m}^{-2}$ pathways are new mitigation scenarios. In addition, there was interest in a scenario with a substantial overshoot in radiative forcing within the 21st century. An overshoot of the $3.4 \mathrm{~W} \mathrm{~m}^{-2}$ pathway was identified as the preferred candidate.

Moreover, 21st century scenarios in ScenarioMIP were also required to be feasible in a narrow sense; i.e., specific scenario outcomes had to be able to be produced with an integrated assessment model (Hare et al., 2010). Each scenario in ScenarioMIP is thus based on a set of internally consistent assumptions leading to a distinct evolution of the underlying socioeconomic systems. The details of the underlying IAM scenarios help identify broader socioeconomic and technological conditions under which specific pathways may be attained in the real world. Feasibility in an IAM model needs to be strictly differentiated, however, from the feasibility of a scenario in the real world, i.e. whether or not the scenario is capable of being attained. The latter hinges on a number of additional factors, such as political and social concerns, which might render feasible model solutions unattainable in the real world (see, e.g, Riahi et al., 2015). There might also be feasible developments in the real world that are not anticipated by the IAM. Results from major international IAM comparison projects (Clarke et al., 2009; Kriegler et al., 2014b; Riahi et al., 2015) indicate that not all scenarios considered in ScenarioMIP may be equally attainable. For example, under specific conditions (e.g., limited availability of technologies or delayed mitigation) some models find the low forcing target of $2.6 \mathrm{~W} \mathrm{~m}^{-2}$ unattainable.

\subsubsection{Choosing SSP-based scenarios}

For each of these eight forcing pathways, an SSP was selected on which to base emissions and land use scenario leading to the desired forcing level in 2100 . The criteria for making these choices revolved around the potential for different SSPs (and emissions/land use scenarios based on them) to 
lead to different climate outcomes, even if they reached the same global average forcing level in 2100 (see Sect. 2.4.2). The prevailing hypothesis is that differences in climate outcomes produced by different scenarios for the same global forcing pathway are likely small relative to regional climate variability, uncertainty across climate models, and uncertainty in impact models used to investigate outcomes of interest to the IAV community (see Sect. 2.4.2). Therefore, climate simulations based on a forcing pathway produced with one SSP scenario will be used in studies aimed at investigating the effects of that same global average forcing pathway but under future socioeconomic conditions given by a different SSP.

However, the degree to which this hypothesis is correct remains an open scientific question. We therefore choose an SSP for each global average forcing pathway by taking into consideration the possibility that the sensitivity of climate outcomes to SSP choice may be larger than anticipated. To account for that possibility, choices were based on one or, when compatible, more of the following goals:

1. Facilitate climate research so that one can learn more about the climate effects of aspects of forcing that may vary by SSP for the same global average forcing pathway, particularly those from land use changes and aerosol emissions.

2. Minimize differences in climate between the outcomes produced by the SSP chosen for a given global average forcing pathway and the climate that would have been produced by choosing other SSPs. These differences would be minimized by choosing an SSP with land use and aerosol pathways that are central relative to other SSPs for the same global average forcing pathway. However, given difficulties in identifying a central scenario (due for example to consideration of multiple variables and regions), in practice this goal implies avoiding SSPs with trends for land use or aerosols that are outliers relative to other SSPs.

3. Ensure consistency with scenarios that are most relevant to the IAM/IAV communities. Not all scenarios for a given global average forcing pathway are anticipated to be equally relevant to IAM and IAV research. This goal implies choosing the SSP that we anticipate to be especially relevant, so that if the climate effects of land use and aerosols turn out to be larger than anticipated, climate simulations will still be consistent with that scenario.

\subsection{Scenarios}

\subsubsection{General features of design}

Table 2 lists all simulations being included in the ScenarioMIP experimental design, divided into two tiers by priority, and the design is summarized visually within the context of the scenario matrix in Fig. 2. Overall, the design has the following general features:

- Four new SSP-based scenarios that update the RCPs, achieving forcing levels of 2.6, 4.5, 6.0, and $8.5 \mathrm{~W} \mathrm{~m}^{-2}$ in the long run.

- Four new "gap" scenarios that define forcing pathways not represented by the RCPs to address new questions of interest for integrated analysis. Two of these fill in gaps between RCPs, one represents a substantial forcing overshoot pathway, and one investigates a forcing pathway below the RCP2.6.

- Scenarios that inform the Paris Agreement goals of limiting warming to below 2 or $1.5^{\circ} \mathrm{C}$. One of the updated RCPs $\left(2.6 \mathrm{~W} \mathrm{~m}^{-2}\right)$ is expected to produce $1.7^{\circ} \mathrm{C}$ warming by 2100 (and would have a likely probability to stay below $2.0^{\circ} \mathrm{C}$ ), while one of the gap scenarios $\left(<2.6 \mathrm{~W} \mathrm{~m}^{-2}\right)$ is designed to produce a global warming that would likely be below $1.5^{\circ} \mathrm{C}$ by 2100 .

- Three long-term extensions of scenarios to 2300 to allow investigation of questions related to climate change beyond 2100 .

- Scenarios that can anchor experiments in a number of other MIPs (see below) to investigate targeted questions, including for example the influence of land use, aerosols and other NTCFs, and overshoot on climate outcomes; carbon cycle feedbacks; and ice sheetclimate interactions.

- Only four scenarios (in Tier 1) with only one simulation per scenario are required for any climate model participating in this MIP.

These scenarios are arranged into two Tiers as follows:

- Tier 1 spans a wide range of uncertainty in future forcing pathways important for research in climate science, IAM, and IAV studies, while also providing key scenarios to anchor experiments in a number of other MIPs (see last column in Table 2). It includes new SSP-based scenarios as continuations of the RCP2.6, RCP4.5, and RCP8.5 forcing levels, and an additional unmitigated forcing scenario (SSP3-7.0) with particularly high aerosol emissions and land use change.

- Tier 2 includes additional scenarios of interest as well as additional ensemble members and long-term extensions. It adds the fourth RCP forcing level, RCP6.0, and two mitigation scenarios achieving relatively low forcing outcomes: SSP4-3.4 (reaching $3.4 \mathrm{~W} \mathrm{~m}^{-2}$ by 2100) addresses policy discussions of mitigation pathways that fall between RCPs 2.6 and 4.5, and a scenario 


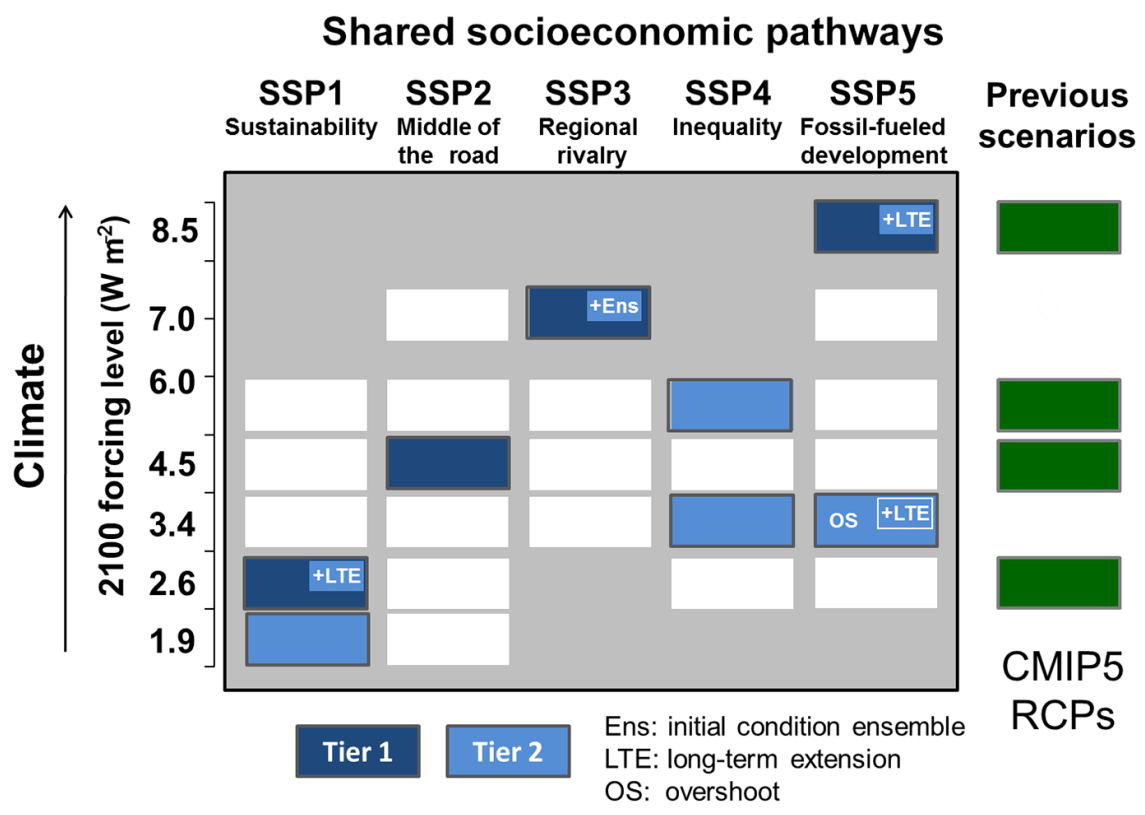

Figure 2. SSP-RCP scenario matrix illustrating ScenarioMIP simulations. Each cell in the matrix indicates a combination of socioeconomic development pathway (i.e., an SSP) and climate outcome based on a particular forcing pathway that current IAM runs have shown to be feasible (Riahi et al., 2016). Dark blue cells indicate scenarios that will serve as the basis for climate model projections in Tier 1 of ScenarioMIP; light blue cells indicate scenarios in Tier 2. An overshoot version of the $3.4 \mathrm{~W} \mathrm{~m}^{-2}$ pathway is also part of Tier 2, as are long-term extensions of SSP5-8.5, SSP1-2.6 and the overshoot scenario, and initial condition ensemble members of SSP3-7.0. White cells indicate scenarios for which climate information is intended to come from the SSP scenario to be simulated for that row. CMIP5 RCPs, which were developed from previous socioeconomic scenarios rather than SSPs, are shown for comparison. Note the SSP1-1.9 scenario indicated here is preliminary (see text).

lower than the RCP 2.6 forcing pathway aims to help inform policy discussion of a global average temperature limit below $1.5^{\circ} \mathrm{C}$ warming relative to pre-industrial levels. It also includes SSP5-3.4-OS, an overshoot pathway, which explores the climate science and policy implications of a peak and decline in forcing during the 21 st century.

\subsubsection{Description of each scenario and its rationale}

We provide here more specific descriptions and justifications for each of the experiments in the design, as well as for some over-arching features of the design. For each of the 21st century scenarios, we describe the relevance of the forcing pathway and also the rationale for the choice of the driving SSP. Figures 3 and 4 summarize the emissions and land use pathways associated with each scenario, and also provide atmospheric concentrations and global average temperature responses as estimated with a simple climate model.

\section{Tier 1: 21st century scenarios}

SSP5-8.5: this scenario represents the high end of the range of future pathways in the IAM literature, updates the RCP8.5 pathway, and is planned to be used by a number of other CMIP6-Endorsed MIPs (Table 2) to help address their scientific questions. SSP5 was chosen for this forcing pathway because it is the only SSP scenario with emissions high enough to produce a radiative forcing of $8.5 \mathrm{~W} \mathrm{~m}^{-2}$ in 2100 .

SSP3-7.0: this scenario represents the medium to high end of the range of future forcing pathways. It fills a gap in CMIP5 forcing pathways that is particularly important because it represents a forcing level that is similar to forcing in the SSP2 baseline scenario as well. Baseline scenarios will be very important to IAV studies interested in quantifying "avoided impacts," which requires comparing impacts in a mitigation scenario with those occurring in an unmitigated baseline scenario. SSP3 was chosen because SSP3-7.0 is a scenario with both substantial land use change (in particular decreased global forest cover) and high NTCF emissions (particularly $\mathrm{SO}_{2}$ ) and therefore will play an important role in LUMIP and AerChemMIP, addressing scenariorelevant questions about the sensitivity of regional climate to land use and aerosols. In addition, SSP3 (combined with this forcing pathway) is especially relevant to IAM/IAV studies because it combines relatively high societal vulnerability (SSP3) with relatively high forcing. This scenario is also the basis for the requested large ensemble (discussed below). 
Table 2. ScenarioMIP experimental design.

\begin{tabular}{llrll}
\hline Scenario name & Forcing category & 2100 forcing $^{1}\left(\mathrm{~W} \mathrm{~m}^{-2}\right)$ & SSP & Use by other MIPs \\
\hline Tier $1^{3}$ & & & & \\
\hline SSP5-8.5 & High & 8.5 & 5 & C $^{4}$ MIP, GeoMIP, ISMIP6, RFMIP \\
SSP3-7.0 & High & 7.0 & 3 & AerChemMIP, LUMIP \\
SSP2-4.5 & Medium & 4.5 & 2 & VIACS AB, CORDEX, GeoMIP, DAMIP, DCPP \\
SSP1-2.6 & Low & 2.6 & 1 & LUMIP \\
\hline
\end{tabular}

Tier 2

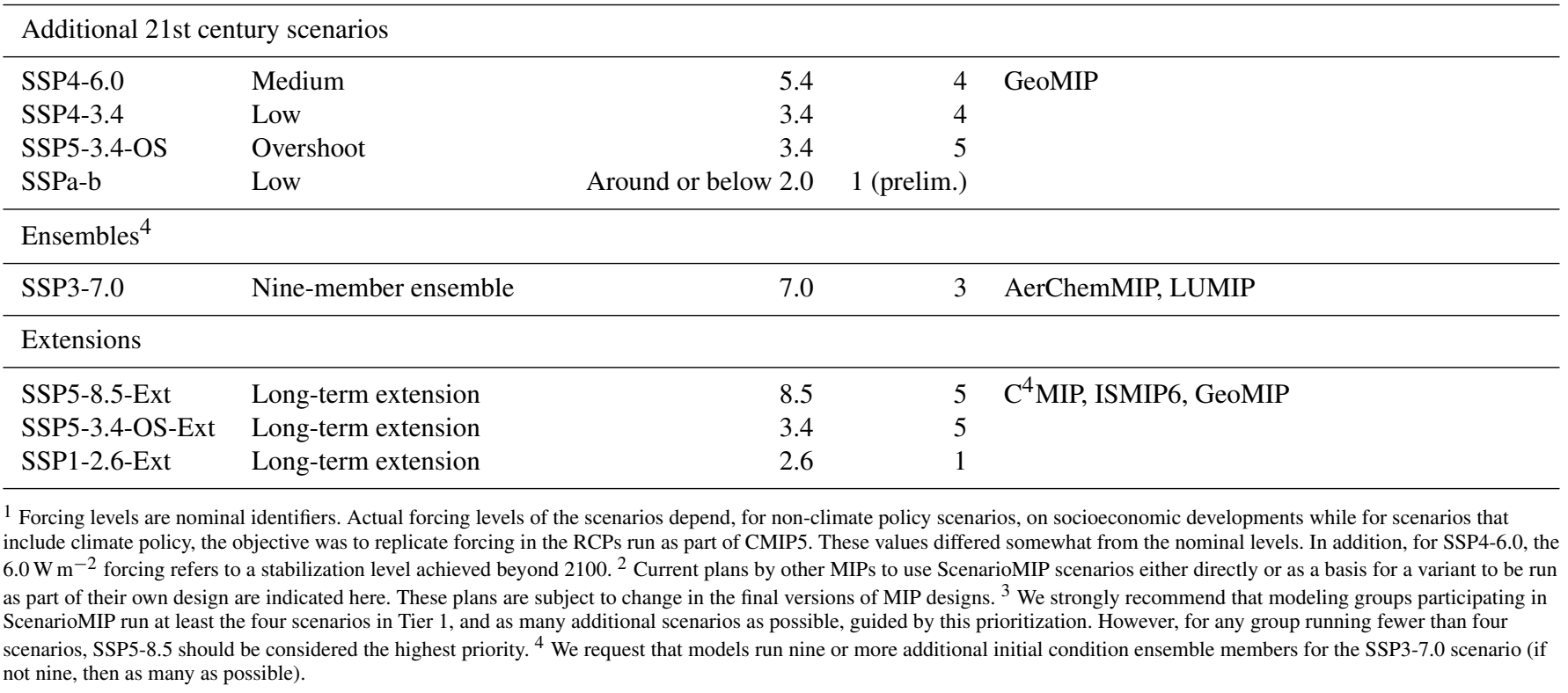

SSP2-4.5: this scenario represents the medium part of the range of future forcing pathways and updates the RCP4.5 pathway. It will be used by several other CMIP6-Endorsed MIPs as a reference experiment, for example by the Coordinated Regional Climate Downscaling Experiment (CORDEX, which will also use SSP5-8.5) for regional downscaling (a product that will be valuable to the IAV community), by Decadal Climate Prediction Project (DCPP) for short-term predictions until 2030, and by the Detection and Attribution MIP (DAMIP) as a continuation of the historical simulations to update regression-based estimates of the role of single forcings beyond 2015 and to run single forcing experiments into the future by using it as the reference scenario. SSP2 was chosen because its land use and aerosol pathways are not extreme relative to other SSPs (and therefore appear as central for the concerns of DAMIP and DCPP), and also because it is relevant to IAM/IAV research as a scenario that combines intermediate societal vulnerability with an intermediate forcing level.

SSP1-2.6: this scenario represents the low end of the range of future forcing pathways in the IAM literature and updates the RCP2.6 pathway. It is anticipated that it will produce a multi-model mean of significantly less than $2{ }^{\circ} \mathrm{C}$ warming by 2100 (Fig. 3), and therefore can support analyses of this policy goal. SSP1 was chosen because it has substantial land use change (in particular increased global forest cover) and will be used by LUMIP to help address their scientific questions. From the IAM/IAV perspective this scenario is highly relevant since it combines low vulnerability with low challenges for mitigation as well as a low forcing signal.

\section{Tier 2: 21st century scenarios}

SSP4-6.0: this scenario fills in the range of medium forcing pathways and updates the RCP6.0 pathway. SSP4 was chosen because together with SSP4-3.4 it could be used to investigate differences in impacts across global average forcing pathways even if the regional climate effects of land use and aerosols turn out to be strong.

SSP4-3.4: this scenario fills a gap at the low end of the range of future forcing pathways. There is substantial mitigation policy interest in scenarios that reach $3.4 \mathrm{~W} \mathrm{~m}^{-2}$ by 2100 , since mitigation costs differ substantially between forcing levels of 4.5 and $2.6 \mathrm{~W} \mathrm{~m}^{-2}$ (depicted by 

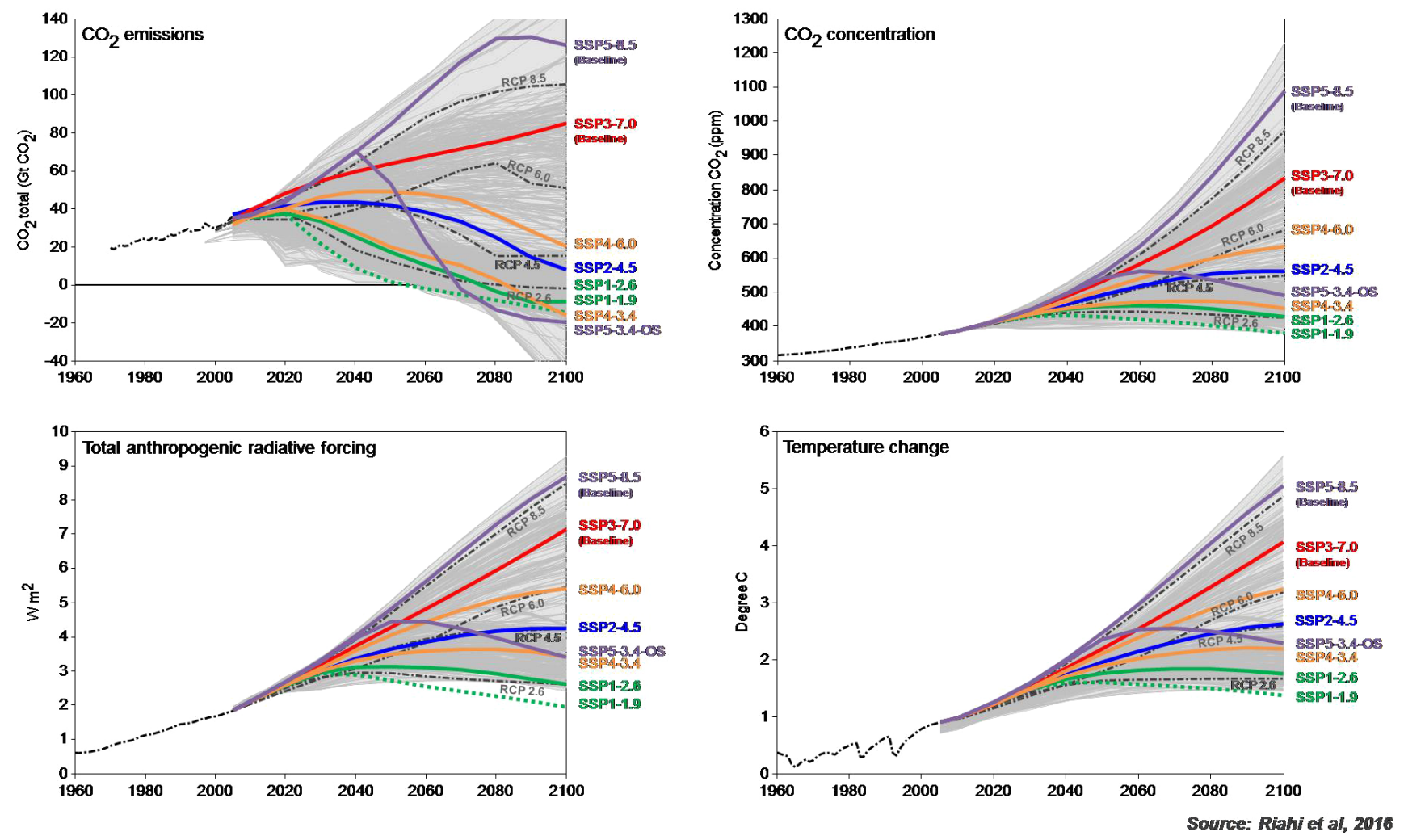

Figure 3. $\mathrm{CO}_{2}$ emissions (a), concentrations (b), anthropogenic radiative forcing (c), and global mean temperature (d) for the 21 st century scenarios in the ScenarioMIP design, from Riahi et al. (2016). Concentration, forcing, and temperature outcomes are calculated with a simple climate model (MAGICC version 6.8.01 BETA; Meinshausen et al., 2011a, b). Temperature outcomes include natural forcing in the historical period; projections assume zero volcanic forcing and maintain 11-year solar forcing cycles, consistent with the CMIP5 approach (Meinshausen et al., 2011c). Gray areas represent the range of scenarios in the scenarios database for the IPCC Fifth Assessment Report (Clarke et al., 2014).

the RCPs, Clarke et al., 2014). Climate model simulations would allow for impacts of a $3.4 \mathrm{~W} \mathrm{~m}^{-2}$ scenario to be compared to those occurring in the 4.5 or $2.6 \mathrm{~W} \mathrm{~m}^{-2}$ scenarios, to evaluate relative costs and benefits of these scenarios. SSP4 was chosen because it is relevant to IAM/IAV research as a scenario with relatively low challenges to mitigation (SSP4) and therefore is a plausible pairing with a relatively low forcing pathway.

SSP5-3.4-OS: this scenario fills a gap in existing climate simulations by investigating the implications of a substantial 21 st century overshoot in radiative forcing relative to a longer-term target. There is substantial interest in the impact, mitigation and adaptation implications of such overshoot, which begins with understanding the climate consequences of such a pathway. This scenario follows SSP5-8.5, an unmitigated baseline scenario, through 2040, at which point aggressive mitigation is undertaken to rapidly reduce emissions to zero by about 2070 and to net negative levels thereafter (Fig. 3). This design will enable climate modeling teams to run the scenario by branching from their Tier 1 SSP5-8.5 simulation in 2040. The final design of the overshoot scenario is subject to additional consideration of specific features including the emissions reduction rates after 2040 and the amount of net negative emissions by the end of the century.

SSPa-b (with b around or below 2.0): this scenario represents the very low end of the range of scenarios in the literature measured by their radiative forcing pathway. Scenarios feasible to produce in an IAM that are significantly below RCP2.6 in terms of radiative forcing are currently rare and have only recently become available in the peer reviewed literature (Rogelj et al., 2015). There is policy interest in scenarios that would inform a possible goal of limiting global mean warming to $1.5^{\circ} \mathrm{C}$ above pre-industrial levels based on the Paris COP21 agreement (UNFCCC, 2015). CMIP5 RCP2.6 projections, which have a median outcome across models of about $1.6^{\circ} \mathrm{C}$ global mean surface temperature in 2100 , and the SSP1-2.6 scenario and its long-term extension, which is estimated to decline to $1.5^{\circ} \mathrm{C}$ warm- 

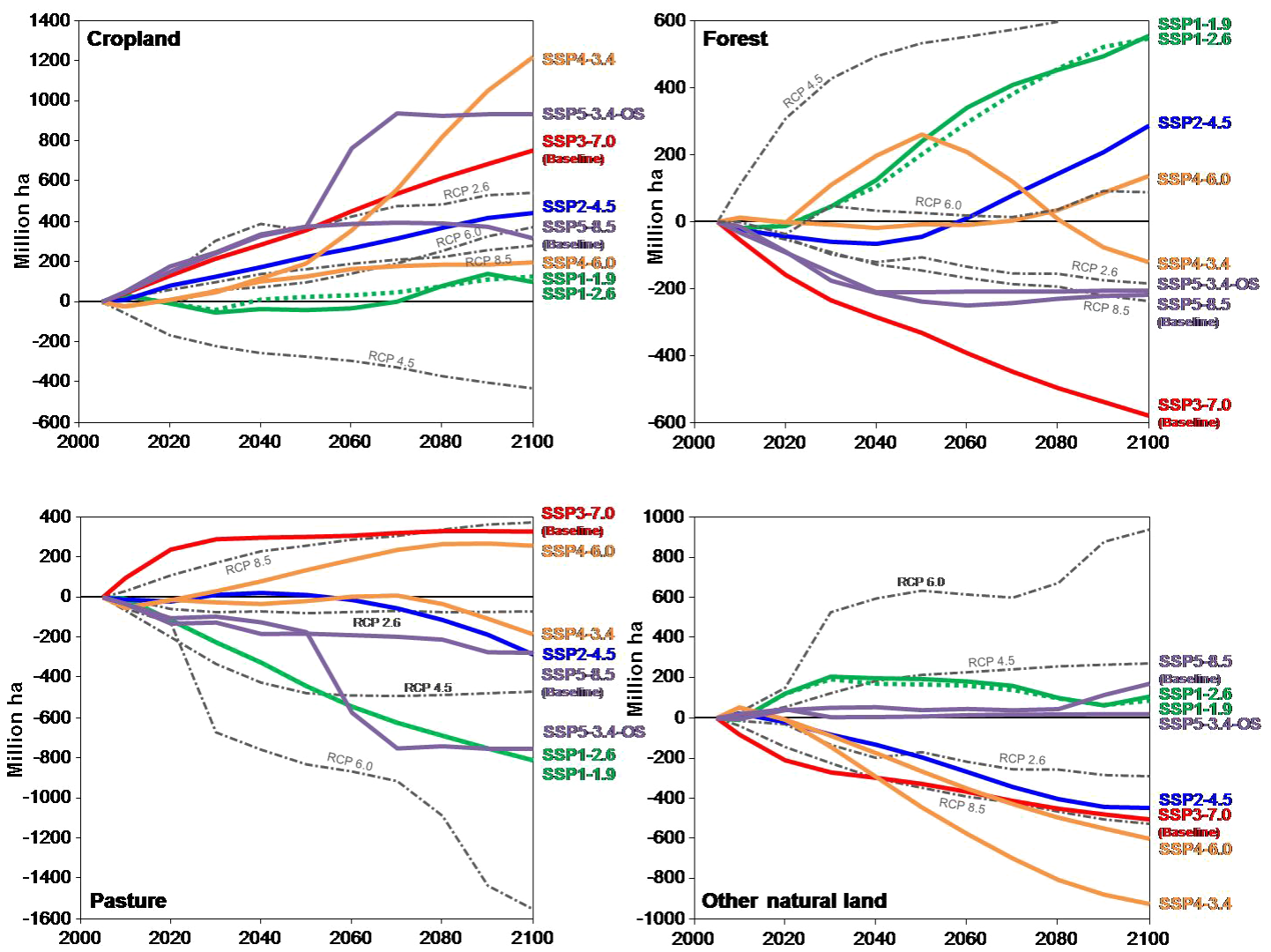

Figure 4. Changes in cropland (a), forest (b), pasture (c), and other natural land (d) for the 21st century scenarios in the ScenarioMIP design, from the same IAM runs used to produce Fig. 3. Land use change for the RCPs (van Vuuren et al., 2011b) is shown for comparison.

ing in the 22nd century (Fig. 5), can inform analyses of the implications of the $1.5^{\circ} \mathrm{C}$ target. To provide additional information on this target, the ScenarioMIP design will include a scenario with forcing substantially below RCP2.6 in 2100. Multiple IAM groups producing SSP-based scenarios have been able to produce preliminary scenarios based on SSP1 that reach about $1.9 \mathrm{~W} \mathrm{~m}^{-2}$ in 2100 , leading to a likely ( $>66 \%$ ) probability of staying below $1.5^{\circ} \mathrm{C}$ in 2100 (but a lower probability around mid-century). We therefore consider SSP1-1.9 to be a preliminary candidate for this scenario. The final design is subject to additional consideration of specific features of this scenario, including the SSP on which it is based, its 2030 emissions level, the likelihood of peak warming exceeding $1.5^{\circ} \mathrm{C}$, and the likelihood of warming being below $1.5^{\circ} \mathrm{C}$ in 2100 . The emission profile will be characterized by a rapid decline to zero and a long period of negative emissions for $\mathrm{CO}_{2}$. Research groups interested in comparing climate outcomes between SSPa-b and SSP1-2.6 (anticipated to lead to below 1.5 and $2{ }^{\circ} \mathrm{C}$, respectively) are encouraged to run additional ensemble members of both scenarios to enhance the detection of differences that can be distinguished from natural variability.

\section{Tier 2: initial condition ensemble}

It is important for scenario-based research to represent the influence of internal variability on climate outcomes. To accommodate this need, while also economizing on model runs, we include an initial condition ensemble for one scenario, based on the assumption that variability estimated for one scenario can be applied to outcomes for others. This initial condition ensemble should be carried out for SSP3-7.0 (a Tier 1 scenario), which has been selected among the Tier 1 experiments for two reasons:

- The relatively high forcing level reached by this scenario by the end of the 21st century will enable the exploration of potential changes in internal variability over a substantial range of global average radiative forcing and temperature change, which could not be assessed if the large ensemble was run for a lower scenario, e.g. SSP2-4.5. Understanding potential changes in variability over a wide range of forcing levels is essential to support the possibility of transferring variability under the large ensemble to other scenarios for which we request only a single ensemble member. 
- SSP3-7.0 has relatively strong land use change and high emissions of NTCFs (unlike the SSP5-8.5 scenario), and therefore has been identified as an important experiment on which variants will be conducted by LUMIP and AerChemMIP to investigate the climate implications of regional differences in land use and aerosol emissions. This topic is also very important to scenariobased studies. In those MIPs, the opportunity to conduct signal-to-noise studies made possible by multiple initial condition ensemble members will be critical.

We request that models run nine additional ensemble members (if not nine, then as many as possible). These additional ensemble members would be considered Tier 2 scenarios (i.e., not required model runs for participation in ScenarioMIP). For all other scenarios, only a single ensemble member is requested.

\section{Tier 2: long-term extensions}

There is strong interest from the climate and impacts communities in long-term extensions of scenarios beyond 2100 to address questions of long term feedbacks and reversibility which might not be apparent from a shorter simulation. The ScenarioMIP long-term extensions will consist of three experiments (Fig. 5).

- Two of these will provide low and high cases for longterm change, comprising extensions for SSP5-8.5 and SSP1-2.6 in a style similar to the extensions of RCP8.5 and RCP2.6 in CMIP5. For the extension of SSP5-8.5, this involves $\mathrm{CO}_{2}$ emissions that are reduced linearly starting in 2100 to less than $10 \mathrm{GtC} \mathrm{yr}^{-1}$ in 2250 , while all other emissions are held constant at 2100 levels. This emissions pathway is estimated to produce equilibrated radiative forcing over the period 2200-2300 at a level similar to the level reached in the long-term extension of RCP8.5 designed for CMIP5 (Meinshausen et al., 2011c; just above $12 \mathrm{~W} \mathrm{~m}^{-2}$ in the simple climate model used in Fig. 5). For SSP1-2.6 the rate of negative carbon emissions from fossil fuels reached in 2100 is extended to 2140 and then increases linearly to zero in 2185, with all other emissions (including $\mathrm{CO}_{2}$ from land use) held constant at 2100 levels, leading to slowly declining forcing that approximately stabilizes beyond 2200 around $2.0 \mathrm{~W} \mathrm{~m}^{-2}$. This extension is expected to achieve a long-term equilibrium temperature of $1.25^{\circ} \mathrm{C}$ above pre-industrial temperatures, based on the simple climate model used in Fig. 5.

- A third case will extend the overshoot scenario (SSP53.4-OS) such that forcing continues to decline beyond 2100 to eventually reach very low forcing levels, in the vicinity of the SSP1-2.6 extension. In this way, the scenario can be seen as an overshoot of the $3.4 \mathrm{~W} \mathrm{~m}^{-2}$ level (which it exceeds and then returns to by about 2100) and of the $2.6 \mathrm{~W} \mathrm{~m}^{-2}$ level, which it returns to in the first half of the 22nd century. The extension assumes that the level of negative $\mathrm{CO}_{2}$ emissions from fossil fuels reached in 2100 remains constant until 2140, and then increase linearly to reach zero by $2190 . \mathrm{CO}_{2}$ emissions from land use are linearly reduced from 2100 to reach the SSP1-2.6 level in 2120 (and then remain at that level thereafter), while all other emissions are held constant at 2100 levels. Like the SSP1-2.6 extension, this pathway also produces a global mean temperature that equilibrates at about $1.25^{\circ} \mathrm{C}$ above pre-industrial temperatures beyond 2200 , but with a higher peak temperature (about $2.4{ }^{\circ} \mathrm{C}$ ) during the 21 st century.

\subsection{Other design features}

\subsubsection{Emissions driven vs. concentration driven}

The scenarios specified in the ScenarioMIP design are to be run as concentration-driven experiments for long-lived greenhouse gases. Such scenarios are more consistent with the "integration" role that these scenarios will play in the broader research community. The conceptual framework for scenario-based research (Sect. 2.3) is based on investigating the implications of alternative climate futures. In order for research using ScenarioMIP climate projections to be as comparable across studies as possible, it is important to ensure that the climate outcomes of the experiments roughly represent the intended forcing levels.

The scenario simulations specified in ScenarioMIP are to be performed in the same configuration as the one used in the CMIP6 historical simulations, ensuring continuity in the climate simulations. In addition, this means that the configuration used for the scenario simulations can benefit from the model evaluation over the historical period. This implies that the modeling groups must use the ScenarioMIPprovided concentrations for all long-lived greenhouse gases $\left(\mathrm{CO}_{2}, \mathrm{CH}_{4}, \mathrm{~N}_{2} \mathrm{O}, \mathrm{CFCs}\right)$. For all other radiatively active constituents (i.e., aerosols and ozone), the modeling groups will use either the ScenarioMIP emissions (from anthropogenic and biomass burning sources only, consistent with the historical emissions) or the CMIP-provided concentrations.

The choice between concentration- and emissions-driven runs relates to a trade-off between the use of scenarios as means of integration across the different communities and the representation of model differences and overall uncertainty. In particular, concentration-driven scenarios do not allow for assessing amplification effects of biogeochemical feedbacks (e.g., in which climate change influences the carbon cycle, producing more emissions and more climate change, and further influencing the carbon cycle) beyond what is included in the model used to generate the ScenarioMIP-provided GHG concentrations. The amplification impacts will however be partially investigated in $\mathrm{C}^{4} \mathrm{MIP}$ and AerChemMIP simulations (see Sect. 3.3.3. below) and 
(a) Fossil fuel $\mathrm{CO}_{2}$ emissions

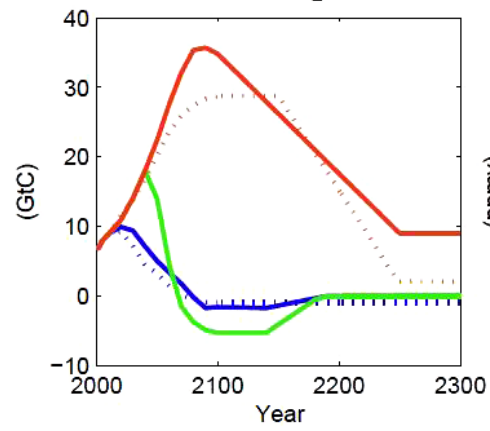

(c) Radiative forcing

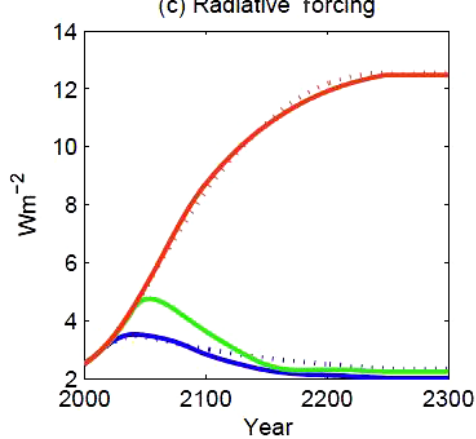

(b) $\mathrm{CO}_{2}$ concentration

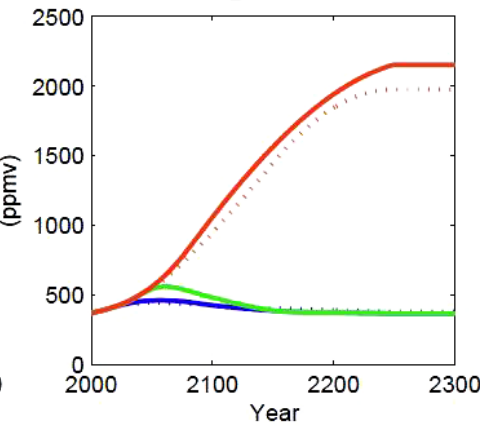

(d) Global mean temperature change

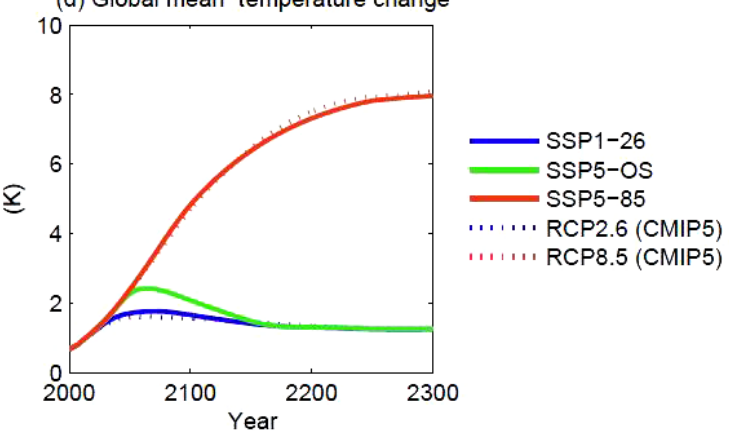

Figure 5. $\mathrm{CO}_{2}$ emissions (a) and concentrations (b), anthropogenic radiative forcing (c), and global mean temperature change (d) for the three long-term extensions. As in Fig. 3, concentration, forcing, and temperature outcomes are calculated with a simple climate model (MAGICC version 6.8.01 BETA; Meinshausen et al., 2011a, b). Outcomes for the CMIP5 versions of the long-term extensions of RCP2.6 and RCP8.5 (Meinshausen et al., 2011c), as calculated with the same model, are shown for comparison.

an assessment of a range of sources of uncertainty will be possible by combining the results from several of the CMIP6Endorsed MIPs.

\subsubsection{Relation to CMIP5}

CMIP6 climate projections will differ from those for CMIP5 due to a new generation of climate models, a new start year for the future scenarios (2015 for CMIP6 vs. 2006 for CMIP5), as well as a new set of scenarios of concentrations, emissions, and land use (Figs. 3 and 4). We recognize that such an approach could be problematic for uncertainty analysis, as the separation of model vs. scenario uncertainty is unclear (Knutti and Sedláček, 2013). For multiple research communities it will be useful to evaluate the difference in climate outcomes that is due to the changes in climate models alone, in particular to understand how the new models have revised our understanding of the climate response to anthropogenic forcing. Such an evaluation is also valuable in order to determine whether CMIP5 and CMIP6 results could be used together in research on impacts and adaptation (and how), or whether IAM and IAV researchers should abandon CMIP5 simulations in favor of CMIP6 simulations when they become available. It is not part of the ScenarioMIP design to carry out simulations that would inform this evaluation. However, it would be interesting to the community if climate modeling teams investigated this question. Possible approaches include running the CMIP6 SSP-based RCPs with single models of the previous (CMIP5) generation, running the CMIP5 RCPs using new (CMIP6) model versions, or carrying out relevant analyses with climate model emulators.

\subsubsection{Relation to other CMIP6-Endorsed MIPs, the DECK, and the CMIP6 historical simulations}

The ScenarioMIP design is intended to provide a basis for targeted scenarios to be run in other CMIP6-Endorsed MIPs in order to address specific questions regarding the sensitivity of climate change outcomes to particular aspects of these scenarios, especially land use and emissions of NTCFs. We describe here current plans for coordinated experiments. A summary of the scenarios within the ScenarioMIP design that are currently part of plans for other CMIP6-Endorsed MIPs is provided in the experimental design table (Table 2).

\section{DECK and CMIP6 historical simulations}

Models participating in CMIP6 must carry out a small set of simulations intended to maintain continuity and document basic characteristics of models across different phases of CMIP. The ScenarioMIP simulations relate to the DECK 
and the CMIP6 historical simulations by using the end of the historical simulations (31 December 2014) as the starting point of future projections (1 January 2015, with consistency ensured through the harmonization of emissions, concentrations, and land use across scenarios and between scenarios and historical simulations). Analysis of present-day climate will likely connect the first few years of the climate projections to the historical runs for those studies using the most up-to-date observational data sets (extending to the years after 2015). An evaluation of the CMP6 historical simulations will provide insights into the reliability of the CMIP6 models and emergent constraints (see Sect. 2.2) can be will be sought to recalibrate the ensemble and to reduce the uncertainty in the response to a given scenario of future forcing. Internal variability characterized through the pre-industrial control runs of the DECK will also serve as a basis of comparison with internal and forced variability simulated with future scenarios.

\section{Aerosols and Chemistry MIP (AerChemMIP)}

AerChemMIP (Collins et al., 2016) has a Tier 1 experiment (with additional Tier 2 and 3 related studies) directed at the sensitivity of climate to near-term climate forcers. This experiment will use the SSP3-7.0 scenario from ScenarioMIP as a starting point and devise a lower air pollutant variant of this scenario by assuming pollution controls, or maximum feasible reductions in air pollutants. In addition, AerChemMIP will make use of the LUMIP land use variant on SSP37.0 (with land use from SSP1-2.6) to study couplings between land use changes and atmospheric chemistry.

\section{Coupled Climate Carbon Cycle MIP ( $\left.\mathrm{C}^{4} \mathrm{MIP}\right)$}

ScenarioMIP will coordinate with $\mathrm{C}^{4} \mathrm{MIP}$ (Jones et al., 2016) on targeted scenarios regarding concentration vs. emissiondriven simulations. While the ScenarioMIP protocol will request $\mathrm{CO}_{2}$ concentration-driven simulations (see above), $\mathrm{C}^{4} \mathrm{MIP} / \mathrm{Tier} 1$ will recommend emission-driven simulations for SSP5-8.5 in order to explore the implications of carbon cycle feedbacks on projected atmospheric $\mathrm{CO}_{2}$ and hence on climate change. As mentioned before, $\mathrm{C}^{4} \mathrm{MIP}$ also has an interest in the extensions of scenarios beyond 2100 (e.g. up to 2300 as in CMIP5). $\mathrm{C}^{4}$ MIP/Tier2 proposes an uncoupled simulation (called BGC mode) for SSP5-8.5 and its extension beyond 2100 in order to investigate climate change impacts on Earth system components that operate on longer timescales (vegetation, permafrost, oceanic circulation and carbon export, etc.). $\mathrm{C}^{4} \mathrm{MIP}$ has expressed high interest in analyzing the ScenarioMIP overshoot scenario.

\section{Detection and Attribution MIP (DAMIP)}

DAMIP (Gillett et al., 2016) plans to use SSP2-4.5 as an anchoring scenario on the basis of which individual forcing simulations extended to the end of the century will be specified and then compared. These experiments are aimed at distinguishing the climate effects of different forcers and facilitating the identification of observational constraints and their use in future projections. SSP2-4.5 will also be used to extend the historical (all forcing) runs to 2020 for use in regression-based estimates of the role of individual forcings within the observational constraint provided by observational records up to the years beyond 2015 (by the time CMIP6 output will be available and the next IPCC assessment report will be written).

\section{Decadal Climate Prediction Project (DCPP)}

DCPP (Boer et al., 2016) plans to use SSP2-4.5 forcings for its initialized short-term predictions out to 2030, and SSP24.5 runs as comparison to evaluate the skills of those predictions.

\section{Geoengineering MIP (GeoMIP)}

GeoMIP (Kravitz et al., 2016) has proposed several experiments that will use two scenarios from ScenarioMIP as a basis from which geoengineering measures would be implemented. Forcing pathways from other ScenarioMIP scenarios would serve as targets for those measures. In particular, SSP5-8.5 would be used as a basis for four experiments: using geoengineering to reduce forcing to a medium forcing (G6Sulfur and G6Solar experiments) or low forcing (G6Sulfur_SSP1-2.6) Tier 1 scenario, investigating the effect of cirrus cloud thinning (G7Cirrus experiment), and investigating the effect of fixed levels of stratospheric aerosol injections (GeoFixed10, 20, 50). The G6Sulfur and G6Solar experiments will also be extended beyond 2100 , with geoengineering applied to reduce forcing from the extension of RCP8.5 down to the forcing level of SSP2-4.5 (the medium forcing Tier 1 scenario). In addition, SSP2-4.5 would be used as a basis for a stratospheric aerosol injection experiment (G4SSA). Overshoot scenarios are also of potential interest to GeoMIP given that geoengineering may be an option for avoiding overshoot.

\section{Ice Sheet MIP for CMIP6 (ISMIP6)}

ISMIP6 (Nowicki et al., 2016) will be proposing two types of experiments that will draw on long-term extensions of a scenario from ScenarioMIP in order to investigate ice sheet response and ice-climate interactions on centennial timescales. In particular, an extension of SSP5-8.5 to 2300 would be used to provide climate model output for offline (uncoupled) ice sheet simulations, and to provide emissions/concentrations for fully coupled ice sheet-climate model experiments.

\section{Land Use MIP (LUMIP)}

LUMIP (Lawrence et al., 2016) plans to design experiments that use two scenarios, SSP3-7.0 and SSP1-2.6, from Sce- 
Table 3. Anthropogenic forcing in ScenarioMIP experiments.

\begin{tabular}{|c|c|c|c|}
\hline Variable & Subcategories & Resolution & Sources \\
\hline Land use & $\begin{array}{l}\text { Crop, pasture, urban area, veg- } \\
\text { etation, forest (latter two both } \\
\text { primary and secondary). }\end{array}$ & $\begin{array}{l}\text { Spatial maps indicating land } \\
\text { use and transition matrices }\end{array}$ & $\begin{array}{l}\text { Methods for historical data and } \\
\text { scenarios developed by LUMIP }\end{array}$ \\
\hline $\begin{array}{l}\text { Emissions of long-lived } \\
\text { greenhouse gases }\end{array}$ & $\mathrm{CO}_{2}, \mathrm{~N}_{2} \mathrm{O}$, halogenated gases & $\begin{array}{l}\text { Spatial maps and/or emissions } \\
\text { by region. }\end{array}$ & $\begin{array}{l}\text { Historical data described in } \\
\text { Meinshausen et al. (2016) }\end{array}$ \\
\hline $\begin{array}{l}\text { Concentrations of long- } \\
\text { lived greenhouse gases }\end{array}$ & $\mathrm{CO}_{2}, \mathrm{~N}_{2} \mathrm{O}$, halogenated gases & Time series & \\
\hline $\begin{array}{l}\text { Emissions of air pollu- } \\
\text { tants }\end{array}$ & $\begin{array}{l}\mathrm{CH}_{4}, \mathrm{SO}_{2}, \mathrm{NO}_{x}, \mathrm{VOC}, \mathrm{CO}, \\
\mathrm{NH}_{y}, \mathrm{BC}, \mathrm{OC}\end{array}$ & Spatial maps & $\begin{array}{l}\text { Historical data described to } \\
\text { be provided by the Com- } \\
\text { munity Emissions Data Sys- } \\
\text { tem (CEDS) project (http: } \\
\text { //www.globalchange.umd.edu/ } \\
\text { ceds/ceds-cmip6-data/) }\end{array}$ \\
\hline Short-lived forcing & Ozone, optical depth & Spatial maps & \\
\hline
\end{tabular}

narioMIP as a basis for testing sensitivity to land use change. The two scenarios would differ both in forcing levels, spanning a range of approximately $4.5 \mathrm{~W} \mathrm{~m}^{-2}$ by 2100 , and in land use change, with substantial deforestation in the SSP37.0 scenario and net afforestation in SSP1-2.6.

\section{Radiative Forcing MIP (RFMIP)}

RFMIP (Pincus et al., 2016) has plans to estimate radiative forcing in different models for a future scenario, preferably a high forcing pathway. At the moment the candidate is SSP58.5 , whose forcings would be applied to current day fixed SSTs (sea surface temperatures) in the idealized setting of the RFMIP experiments.

\section{Vulnerability, impacts, adaptation and climate services (VIACS) advisory board}

Researchers examining the consequences of climate change and potential adaptations are a key user group of CMIP outputs and products. ScenarioMIP will establish a close link with the impact community through the VIACS Advisory Board (Ruane et al., 2016) and other relevant groups to facilitate integrated research that leads to a better understanding not only of the physical consequences of these scenarios on the climate system, but also of the climate impact on societies and ecosystems. In particular ScenarioMIP will link with the VIACS Advisory Board to ensure that the climate model output from the scenarios allows for sector-specific indices being derived (e.g., heat damage degree days for ecosystems, consecutive dry days for agriculture and water resources).

\section{Inputs (forcings) and outputs}

The forcings required to run the climate model simulations of the experiments listed in Table 2 include global spatial distri- butions of emissions and concentrations of greenhouse gases, ozone concentrations (or precursors, for emissions-driven experiments), and aerosols and land use, at a level of spatial detail suitable for the generation of climate models that will be used in CMIP6. Table 3 provides a list of input variables. These projections will be the results of IAM-based scenarios at the level of world regions with a time horizon of 20152100. The underlying IAM scenarios are documented in a Special Issue in Global Environmental Change (Riahi et al., 2016).

The IAM output will be harmonized to be consistent with recent historical data for land use, greenhouse gas and air pollutant emissions and concentrations (which will also be used for the historical runs in CMIP6). In a subsequent step the data will be downscaled to spatial grids. This process will basically be done using the methods applied earlier for the RCPs (Van Vuuren et al., 2011a). The methods and results for land use data are described in detail in Hurtt et al. (2016).

Figures 3 and 5 show preliminary versions of the forcing pathways associated with the eight 21 st century scenarios and three long-term extensions, as calculated by the IAMs.

Future simulations will also require specification of natural forcings, in particular solar forcing and volcanic emissions. For CMIP6, these forcings will differ from what was used in CMIP5. Solar time series will be provided as described on the SOLARIS-HEPPA website at http:// solarisheppa.geomar.de/cmip6 and in Matthes et al. (2016). Volcanic forcing will be ramped up from the value at the end of the historical simulation period (2015) over 10 years to the same constant value prescribed for the piControl simulations in the DECK, and then will be kept fixed.

ScenarioMIP has not defined a separate data request for CMIP6, but rather recommends that variables that are requested for the DECK and the CMIP6 historical simulations are also stored for the future climate model simulations. This includes climate model output of interest to the IAM and IAV 
communities as identified by the CMIP6 VIACS advisory board, see the contribution on the CMIP6 data request to this Special Issue for further details.

\section{Conclusions}

The ScenarioMIP experimental design aims to facilitate a wide range of integrated studies across the climate science, integrated assessment modeling and IAV communities. It will do so as one element of a larger scenario process that also includes a new set of societal development pathways (the SSPs) over the 21st century. Integrating climate simulations from ScenarioMIP with the SSPs or other characterizations of societal futures will allow for analyses of future mitigation, adaptation, and impacts that account for both climate and societal change in a coherent fashion. Multi-model climate model projections from ScenarioMIP will also provide the basis for investigating a number of targeted scientific questions regarding the role of specific forcings and the contribution of forcing uncertainty to the total uncertainty budget, the effect of a peak and decline in forcing, and longterm climate system outcomes beyond the 21 st century. The multi-model approach will allow for a better characterization of uncertainty in climate outcomes than would otherwise be possible, and the design also calls for a large initial condition ensemble that will allow for representation of internal variability in impact studies as well as improved signal detection in experiments in other MIPs that will carry out variants of this scenario. Ultimately, the success of ScenarioMIP lies in the broad participation of the CMIP6 modeling groups in Tier 1 experiments, but also in Tier 2 experiments since they offer the opportunity to study additional interesting and new science and policy questions.

Beyond the establishment of the experimental design, remaining tasks for ScenarioMIP include ensuring that emissions, concentrations, and land use scenarios from integrated assessment models are provided to participating climate models as inputs for their simulations. While ScenarioMIP will participate in this process, primary leadership for the emissions will come from separate groups. The IAMC Scenarios Working Group is coordinating the production of SSP-based IAM scenarios, which include emissions and land use generated at the level of world regions. That group will also coordinate a process for harmonizing emissions across IAMs to be consistent with a common estimate of recent historical data, as well for downscaling emissions to the grid cell level needed for climate model input. Land use scenarios produced by IAMs will be downscaled using a methodology developed within LUMIP, in coordination with the IAMC working group.

Once climate model simulations for ScenarioMIP have been completed, the SSC will coordinate some of the first analyses of results, aiming at delivering the initial description of the new scenarios' principal physical climate outcomes, ideally in comparison to the CMIP5 RCP outcomes. However, we do not include a specific comprehensive analysis plan in this paper, because the research communities that are interested in analyzing our MIP results are well established, diverse, and large. Individual modeling and research groups and investigators will likely self-organize to carry out studies of future changes on variables, regional domains, impacts, and mitigation measures of interest.

\section{Data availability}

The climate model output from ScenarioMIP experiments described in this paper will be distributed through the Earth System Grid Federation (ESGF) with DOIs assigned. As in CMIP5, the model output will be freely accessible through data portals after registration. In order to document CMIP6's impact and enable ongoing support of CMIP, users are obligated to acknowledge CMIP6 and the participating modeling groups (see details on the CMIP panel website at http://www. wcrp-climate.org/index.php/wgcm-cmip/about-cmip). In order to run the experiments, data sets for future natural and anthropogenic forcings are required. The recommendation for the future solar forcing data sets and background volcanic aerosol are described in separate contributions to this Special Issue. These data sets for natural forcings will be made available through the ESGF with version control and DOIs assigned. All other forcing data (land use, emissions, concentrations, extensions) required for the future SSP-RCPs selected in ScenarioMIP will be made publicly accessible on the SSP database at https://tntcat.iiasa.ac.at/SspDb/dsd? Action $=$ htmlpage $\&$ page $=$ about.

Acknowledgements. CRESCENDO project members (V. Eyring, P. Friedlingstein, E. Kriegler, R. Knutti, J. Lowe, K. Riahi, D. van Vuuren) acknowledge funding received from the Horizon 2020 European Union's Framework Programme for Research and Innovation under grant agreement no. 641816. C. Tebaldi, G. A. Meehl and B. M. Sanderson acknowledge the support of the Regional and Global Climate Modeling Program (RGCM) of the U.S. Department of Energy's, Office of Science (BER), Cooperative Agreement DE-FC02-97ER62402.

Edited by: S. Easterbrook

Reviewed by: two anonymous referees

\section{References}

Alfieri, L., Feyen, L., Dottori, F., and Bianchi, A.: Ensemble flood risk assessment in Europe under high end climate scenarios, Global Environ. Chang., 35, 199-212, doi:10.1016/j.gloenvcha.2015.09.004, 2015.

Allen, M. R. and Ingram, W. J.: Constraints on future changes in climate and the hydrologic cycle, Nature, 419, p. 224, 2002. 
Arnell, N. W. and Lloyd-Hughes, B.: The global-scale impacts of climate change on water resources and flooding under new climate and socio-economic scenarios, Climatic Change, 122, 127140, doi:10.1007/s10584-013-0984-4, 2014.

Bauer, N., Calvin, K., Emmerling, J., Fricko, O., Fujimori S., Hilaire, J., Eom, J., Krey, V., Kriegler, E., Mouratiadou, I., Sytze de Boer, H., van den Berg, M., Carrara, S., Daioglou, V., Drouet, L., Edmonds, J. E., Gernaat, D., Havlik, P., Johnson, N., Klein, D., Kyle, P., Marangoni, G., Masui, T., Pietzcker, R. C., Strubegger, M., Wise, M., Riahi, K., van Vuuren, D.P .: Shared Socio-Economic Pathways of the Energy Sector - Quantifying the Narratives, Global Environ. Chang., doi:10.1016/j.gloenvcha.2016.07.006, in press, 2016.

Biewald, A., Lotze-Campen, H., Otto, I., Brinckmann, N., Bodirsky, B., Weindl, I., Popp, A., and Schellnhuber, H. J.: The impacts of climate change on costs of food and people exposed to hunger at subnational scale, PIK Report 128, Potsdam Institute for Climate Impact Research (PIK), Potsdam, Germany, 2015.

Boé, J. L., Hall, A., and Qu, X.: September sea-ice cover in the Arctic Ocean projected to vanish by 2100 , Nat. Geosci., 2, 341343, 2009.

Boer, G. J., Smith, D. M., Cassou, C., Doblas-Reyes, F., Danabasoglu, G., Kirtman, B., Kushnir, Y., Kimoto, M., Meehl, G. A., Msadek, R., Mueller, W. A., Taylor, K., and Zwiers, F.: The Decadal Climate Prediction Project, Geosci. Model Dev. Discuss., doi:10.5194/gmd-2016-78, in review, 2016.

Bracegirdle, T. J. and Stephenson, D. B.: On the Robustness of Emergent Constraints Used in Multimodel Climate Change Projections of Arctic Warming, J. Climate, 26, 669-678, 2013.

Clarke, L., Edmonds, J., Krey, V., Richels, R., Rose, S., and Tavoni, M.: International climate policy architectures: Overview of the EMF 22 International Scenarios, Energ. Econ., 31, S64-S81, 2009.

Clarke, L., Jiang, K., Akimoto, K., Babiker, M., Blanford, G., Fisher-Vanden, K., Hourcade, J.-C., Krey, V., Kriegler, E., Löschel, A., McCollum, D., Paltsev, S., Rose, S., Shukla, P.R., Tavoni, M., van der Zwaan, B. C. C., and van Vuuren, D. P.: Assessing Transformation Pathways, in: Climate Change 2014: Mitigation of Climate Change. Contribution of Working Group III to the Fifth Assessment Report of the Intergovernmental Panel on Climate Change, edited by: Edenhofer, O., Pichs-Madruga, R., Sokona, Y., Farahani, E., Kadner, S., Seyboth, K., Adler, A., Baum, I., Brunner, S., Eickemeier, P., Kriemann, B., Savolainen, J., Schlömer, S., von Stechow, C., Zwickel, T., and Minx, J. C., Cambridge University Press, Cambridge, United Kingdom and New York, NY, USA, 2014.

Collins, W. J., Lamarque, J.-F., Schulz, M., Boucher, O., Eyring, V., Hegglin, M. I., Maycock, A., Myhre, G., Prather, M., Shindell, D., and Smith, S. J.: AerChemMIP: Quantifying the effects of chemistry and aerosols in CMIP6, Geosci. Model Dev. Discuss., doi:10.5194/gmd-2016-139, in review, 2016.

Cox, P. M., Pearson, D., Booth, B. B., Friedlingstein, P., Huntingford, C., Jones, C. D., and Luke, C. M.: Sensitivity of tropical carbon to climate change constrained by carbon dioxide variability, Nature, 494, 341-344, 2013.

Dellink, R., Chateau, J., Lanzi, E., and Magne, B.: Long-term economic growth projections in the Shared Socioeconomic Pathways, Global Environ. Chang., doi:10.1016/j.gloenvcha.2015.06.004, online first, 2015.
Dong, W., Liu, Z., Liao, H., Tang, Q., and Li, X.: New climate and socio-economic scenarios for assessing global human health challenges due to heat risk, Climatic Change, 4, 505-518, doi:10.1007/s10584-015-1372-8, 2015.

Eyring, V., Bony, S., Meehl, G. A., Senior, C. A., Stevens, B., Stouffer, R. J., and Taylor, K. E.: Overview of the Coupled Model Intercomparison Project Phase 6 (CMIP6) experimental design and organization, Geosci. Model Dev., 9, 1937-1958, doi:10.5194/gmd-9-1937-2016, 2016.

Fasullo, J. T. and Trenberth, K. E.: A Less Cloudy Future: The Role of Subtropical Subsidence in Climate Sensitivity, Science, 338, 792-794, 2012.

Fasullo, J. T., Sanderson, B. M., and Trenberth, K. E.: Recent Progress in Constraining Climate Sensitivity With Model Ensembles, Current Climate Change Reports, 1, 268-275, 2015.

Gillett, N. P., Shiogama, H., Funke, B., Hegerl, G., Knutti, R., Matthes, K., Santer, B. D., Stone, D., and Tebaldi, C.: Detection and Attribution Model Intercomparison Project (DAMIP), Geosci. Model Dev. Discuss., doi:10.5194/gmd-2016-74, in review, 2016.

Hall, A. and Qu, X.: Using the current seasonal cycle to constrain snow albedo feedback in future climate change, Geophys. Res. Lett., 33, L03502, doi:10.1029/2005GL025127, 2006.

Hare, W., Lowe, J., Rogelj, J., Sawin, E., van Vuuren, D., Bosetti, V., Hanaoka, T., Kejun, J., Matthews, B., O’Neill, B. C., Ranger, N., and Riahi, K.: Which emission pathways are consistent with a $2{ }^{\circ} \mathrm{C}$ or $1.5^{\circ} \mathrm{C}$ temperature limit?, in: The Emissions Gap Report: Are the Copenhagen Accord Pledges Sufficient to Limit Global Warming to $2^{\circ} \mathrm{C}$ or $1.5^{\circ} \mathrm{C}$ ? A preliminary assessment (UNEP, Nairobi, Kenya), 23-31, 2010.

Hejazi, M. I., Voisin, N., Liu, L., Bramer, L. M., Fortin, D. C., Hathaway, J. E., Huang, M., Kyle, P., Leung, L. R., Li, H.-Y., Liu, Y., Patel, P. L., Pulsipher, T. C., Rice, J. S., Tesfa, T. K., Vernon, C. R., and Zhou, Y.: 21st century United States emissions mitigation could increase water stress more than the climate change it is mitigating, Proc. Natl. Acad. Sci USA, 112, 10635-10640, doi:10.1073/pnas.1421675112, 2015.

Herger, N., Sanderson, B. M., and Knutti, R.: Improved pattern scaling approaches for the use in climate impact studies, Geophys. Res. Lett., 42, 3486-3494, doi:10.1002/2015GL063569, 2015.

Huber, M., Mahlstein, I., Wild, M., Fasullo, J., and Knutti, R.: Constraints on climate sensitivity from radiation patterns in climate models, J. Climate, 24, 1034-1052, 2011.

IPCC: Climate Change 2001: Mitigation of Climate Change, Contribution of Working Group III to the Third Assessment Report of the Intergovernmental Panel on Climate Change, edited by: Davidson, O. R. and Mertz, B., Cambridge University Press, Cambridge, United Kingdom and New York, NY, USA, 2001.

IPCC: Climate Change 2007: The physical science basis: Contribution of Working Group I to the Fourth Assessment Report of the Intergovernmental Panel on Climate Change, edited by: Solomon, S., Qin, D., Manning, M., Chen, Z., Marquis, M., Averyt, K. B., Tignor, M., and Miller, H. L., Cambridge University Press, Cambridge, United Kingdom and New York, NY, USA, 996 pp., 2007a.

IPCC: Climate Change 2007: Impacts, Adaptation and Vulnerability: Contribution of Working Group II to the Fourth Assessment Report of the Intergovernmental Panel on Climate Change, edited by: Parry, M. L., Canziani, O. F., Palutikof, J. P., van der Linden, 
P. J., and Hanson, C. E., Cambridge University Press, Cambridge, United Kingdom and New York, NY, USA, 976 pp., 2007b.

IPCC: Climate Change 2007: Mitigation of Climate Change, Contribution of Working Group III to the Fourth Assessment Report of the Intergovernmental Panel on Climate Change, edited by: Metz, B., Davidson, O. R., Bosch, P. R., Dave, R., and Meyer, L. A., Cambridge University Press, Cambridge, United Kingdom and New York, NY, USA, 2007c.

IPCC: Climate Change 2013: The Physical Science Basis, Contribution of Working Group I to the Fifth Assessment Report of the Intergovernmental Panel on Climate Change, edited by: Stocker, T. F., Qin, D., Plattner, G.-K., Tignor, M., Allen, S. K., Boschung, J., Nauels, A., Xia, Y., Bex, V., and Midgley, P. M., Cambridge University Press, Cambridge, United Kingdom and New York, NY, USA, 1535 pp., 2013.

IPCC: Climate Change 2014: Impacts, Adaptation, and Vulnerability. Part A: Global and Sectoral Aspects. Contribution of Working Group II to the Fifth Assessment Report of the Intergovernmental Panel on Climate Change, edited by: Field, C. B., Barros, V. R., Dokken, D. J., Mach, K. J., Mastrandrea, M. D., Bilir, T. E., Chatterjee, M., Ebi, K. L., Estrada, Y. O., Genova, R. C., Girma, B., Kissel, E. S., Levy, A. N., MacCracken, S., Mastrandrea, P. R., and White, L. L., Cambridge University Press, Cambridge, United Kingdom and New York, NY, USA, 1132 pp., 2014a.

IPCC: Climate Change 2014: Impacts, Adaptation, and Vulnerability. Part B: Regional Aspects. Contribution of Working Group II to the Fifth Assessment Report of the Intergovernmental Panel on Climate Change, edited by: Barros, V. R., Field, C. B., Dokken, D. J., Mastrandrea, M. D., Mach, K. J., Bilir, T. E., Chatterjee, M., Ebi, K. L., Estrada, Y. O., Genova, R. C., Girma, B., Kissel, E. S., Levy, A. N., MacCracken, S., Mastrandrea, P. R., and White, L. L., Cambridge University Press, Cambridge, United Kingdom and New York, NY, USA, 688 pp., 2014 b.

IPCC: Climate Change 2014: Mitigation of Climate Change. Contribution of Working Group III to the Fifth Assessment Report of the Intergovernmental Panel on Climate Change, edited by: Edenhofer, O., Pichs-Madruga, R., Sokona, Y., Farahani, E., Kadner, S., Seyboth, K., Adler, A., Baum, I., Brunner, S., Eickemeier, P., Kriemann, B., Savolainen, J., Schlömer, S., von Stechow, C., Zwickel, T., and Minx, J. C., Cambridge University Press, Cambridge, United Kingdom and New York, NY, USA, 2014c.

Jiang, L. and O'Neill, B. C.: Global urbanization projections for the Shared Socioeconomic Pathways, Global Environ. Chang., doi:10.1016/j.gloenvcha.2015.03.008, online first, 2015.

Jones, C. D., Arora, V., Friedlingstein, P., Bopp, L., Brovkin, V., Dunne, J., Graven, H., Hoffman, F., Ilyina, T., John, J. G., Jung, M., Kawamiya, M., Koven, C., Pongratz, J., Raddatz, T., Randerson, J. T., and Zaehle, S.: C4MIP - The Coupled Climate-Carbon Cycle Model Intercomparison Project: experimental protocol for CMIP6, Geosci. Model Dev., 9, 2853-2880, doi:10.5194/gmd-92853-2016, 2016.

$\mathrm{KC}, \mathrm{S}$. and Lutz, W.: The human core of the shared socioeconomic pathways: Population scenarios by age, sex and level of education for all countries to 2100, Global Environ. Chang., doi:10.1016/j.gloenvcha.2014.06.004, online first, 2014.

Klein, S. A. and Hall, A.: Emergent Constraints for Cloud Feedbacks, Current Climate Change Reports, 1, 276-287, 2015.
Knutti, R. and Sedlacek, J.: Robustness and uncertainties in the new CMIP5 climate model projections, Nature Climate Change, 3, 369-373, 2013.

Knutti, R. and Tomassini, L.: Constraints on the transient climate response from observed global temperature and ocean heat uptake, Geophys. Res. Lett., 35, L09701, doi:10.1029/2007GL032904, 2008.

Knutti, R., Meehl, G. A., Allen, M. R., and Stainforth, D. A.: Constraining climate sensitivity from the seasonal cycle in surface temperature, J. Climate, 19, 4224-4233, 2006.

Kravitz, B., Robock, A., Tilmes, S., Boucher, O., English, J. M., Irvine, P. J., Jones, A., Lawrence, M. G., MacCracken, M., Muri, H., Moore, J. C., Niemeier, U., Phipps, S. J., Sillmann, J., Storelvmo, T., Wang, H., and Watanabe, S.: The Geoengineering Model Intercomparison Project Phase 6 (GeoMIP6): simulation design and preliminary results, Geosci. Model Dev., 8, 33793392, doi:10.5194/gmd-8-3379-2015, 2015.

Kriegler, E., O’Neill, B. C., Hallegatte, S., Kram, T., Lempert, R. J., Moss, R. H., and Wilbanks, T.: The need for and use of socio-economic scenarios for climate change analysis: a new approach based on shared socio-economic pathways, Global Environ. Chang., 22, 807-822, doi:10.1016/j.gloenvcha.2012.05.005, 2012.

Kriegler, E., Edmonds, J., Hallegatte, S., Ebi, K., Kram, T., Riahi, K., Winkler, H., and van Vuuren, D.: A new scenario framework for climate change research: the concept of shared climate policy assumptions, Climatic Change, 122, 401-414, 2014 a.

Kriegler, E., Weyant, J. P., Blanford, G. J., Krey, V., Clarke, L., Edmonds, J., Fawcett, A., Luderer, G., Riahi, K., Richels, R., Rose, S. K., Tavoni, M., and van Vuuren, D. P.: The role of technology for achieving climate policy objectives: Overview of the EMF 27 study on global technology and climate policy strategies, Climatic Change, 123, 353-367, 2014b.

Lawrence, D. M., Hurtt, G. C., Arneth, A., Brovkin, V., Calvin, K. V., Jones, A. D., Jones, C. D., Lawrence, P. J., de NobletDucoudré, N., Pongratz, J., Seneviratne, S. I., and Shevliakova, E.: The Land Use Model Intercomparison Project (LUMIP) contribution to CMIP6: rationale and experimental design, Geosci. Model Dev., 9, 2973-2998, doi:10.5194/gmd-9-29732016, 2016.

Mahlstein, I. and Knutti, R.: September Arctic sea ice predicted to disappear near $2^{\circ} \mathrm{C}$ global warming above present, J. Geophys. Res., 117, D06104, doi:10.1029/2011JD016709, 2012.

Massonnet, F., Fichefet, T., Goosse, H., Bitz, C. M., PhilipponBerthier, G., Holland, M. M., and Barriat, P.-Y.: Constraining projections of summer Arctic sea ice, The Cryosphere, 6, 13831394, doi:10.5194/tc-6-1383-2012, 2012.

Matthes, K., Funke, B., Anderson, M. E., Barnard, L., Beer, J., Charbonneau, P., Clilverd, M. A., Dudok de Wit, T., Haberreiter, M., Hendry, A., Jackman, C. H., Kretschmar, M., Kruschke, T., Kunze, M., Langematz, U., Marsh, D. R., Maycock, A., Misios, S., Rodger, C. J., Scaife, A. A., Seppälä, A., Shangguan, M., Sinnhuber, M., Tourpali, K., Usoskin, I., van de Kamp, M., Verronen, P. T., and Versick, S.: Solar Forcing for CMIP6 (v3.1), Geosci. Model Dev. Discuss., doi:10.5194/gmd-2016-91, in review, 2016.

Meehl, G., Covey, C., Delworth, T., Latif, M., McAvaney, B., Mitchell, J., Stouffer, R. and Taylor, K.: The WCRP CMIP3 multimodel dataset, B. Am. Meteorol. Soc., 88, 1383-1394, 2007. 
Meehl, G. A., Moss, R. H., Taylor, K. E., Eyring, V., Stouffer, R. J., Bony, S., and Stevens, B.: Climate Model Intercomparisons: Preparing for the Next Phase, Eos Trans., AGU, 95, 77, 2014.

Meinshausen, M., Raper, S. C. B., and Wigley, T. M. L.: Emulating coupled atmosphere-ocean and carbon cycle models with a simpler model, MAGICC6 - Part 1: Model description and calibration, Atmos. Chem. Phys., 11, 1417-1456, doi:10.5194/acp11-1417-2011, 2011a.

Meinshausen, M., Wigley, T. M. L., and Raper, S. C. B.: Emulating atmosphere-ocean and carbon cycle models with a simpler model, MAGICC6 - Part 2: Applications, Atmos. Chem. Phys., 11, 1457-1471, doi:10.5194/acp-11-1457-2011, 2011 b.

Meinshausen, M., Smith, S. J., Calvin, K., Daniel, J. S., Kainuma, M. L. T., Lamarque, J.-F., Matsumoto, K., Montzka, S. A., Raper, S. C. B., Riahi, K., Thomson, A., Velders, G. J. M., and van Vuuren, D. P.: The RCP greenhouse gas concentrations and their extensions from 1765 to 2300, Climatic Change, 109, 213-241, 2011c.

Meinshausen, M., Vogel, E., Nauels, A., Lorbacher, K., Meinshausen, N., Etheridge, D., Fraser, P., Montzka, S. A., Rayner, P., Trudinger, C., Krummel, P., Beyerle, U., Cannadell, J. G., Daniel, J. S., Enting, I., Law, R. M., O’Doherty, S., Prinn, R. G., Reimann, S., Rubino, M., Velders, G. J. M., Vollmer, M. K., and Weiss, R.: Historical greenhouse gas concentrations, Geosci. Model Dev. Discuss., doi:10.5194/gmd-2016-169, in review, 2016.

Moss, R., Babiker, M., Brinkman, S., Calvo, E., Carter, T., Edmonds, J., Elgizouli, I., Emori, S., Erda, L., Hibbard, K., Jones, R., Kainuma, M., Kelleher, J., Lamarque, J.-F., Manning, M., Matthews, B., Meehl, J., Meyer, L., Mitchell, J., Nakicenovic, N., O’Neill, B., Pichs, R., Riahi, K., Rose, S., Runci, P., Stouffer, R., van Vuuren, D., Weyant, J., Wilbanks, T., van Ypersele, J.-P., and Zurek, M. : Towards New Scenarios for Analysis of Emissions, Climate Change, Impacts, and Response Strategies, Technical Summary. Intergovernmental Panel on Climate Change, Geneva, 25 pp., 2008.

Moss, R. H., Edmonds, J. A., Hibbard, K. A., Manning, M. R., Rose, S. K., van Vuuren, D. P., Carter, T. R., Emori, S., Kainuma, M., Kram, T., Meehl, G. A., Mitchell, J. F. B., Nakicenovic, N., Riahi, K., Smith, S. J., Stouffer, R.J., Thomson, A. M., Weyant, J. P., and Wilbanks, T. J.: The next generation of scenarios for climate change research and assessment, Nature, 463, 747-756, 2010.

Myhre, G., Shindell, D., Bréon, F.-M., Collins, W., Fuglestvedt, J., Huang, J., Koch, D., Lamarque, J.-F., Lee, D., Mendoza, B., Nakajima, T., Robock, A., Stephens, G., Takemura, T., and Zhang, H.: Anthropogenic and Natural Radiative Forcing, in: Climate Change 2013: The Physical Science Basis, Contribution of Working Group I to the Fifth Assessment Report of the Intergovernmental Panel on Climate Change, edited by: Stocker, T. F., Qin, D., Plattner, G.-K., Tignor, M., Allen, S. K., Boschung, J., Nauels, A., Xia, Y., Bex, V., and Midgley, P. M., Cambridge University Press, Cambridge, United Kingdom and New York, NY, USA, 2013.

Nakićenović, N., Davidson, O., Davis, G., Grübler, A., Kram,T., Lebre La Rovere, E., Metz, B., Morita, T., Pepper, W., Pitcher, H., Sankovshi, A., Shukla, P., Swart, R., Watson, R., and Dadi, Z.: Special Report on Emissions Scenarios: A Special Report of Working Group III of the Intergovernmental Panel on Climate
Change, Cambridge University Press, Cambridge, United Kingdom, 599 pp., 2000.

Nowicki, S. M. J., Payne, T., Larour, E., Seroussi, H., Goelzer, H., Lipscomb, W., Gregory, J., Abe-Ouchi, A., and Shepherd, A.: Ice Sheet Model Intercomparison Project (ISMIP6) contribution to CMIP6, Geosci. Model Dev. Discuss., doi:10.5194/gmd-2016105, in review, 2016.

O’Neill, B. C., Lawrence, D., and Larmarque, J.-F.: Developing climate model comparisons, Eos, 95, p. 462, 2014a.

O’Neill, B. C., Kriegler, E., Riahi, K., Ebi, K., Hallegatte, S., Carter, T. R., Mathur, R., and van Vuuren, D. P.: A new scenario framework for climate change research: The concept of shared socioeconomic pathways, Climatic Change, 122, 387-400, $2014 \mathrm{~b}$.

O’Neill, B. C., Kriegler, E., Ebi, K. L., Kemp-Benedict, E., Riahi, K., Rothman, D. S., van Ruijven, B. J., van Vuuren, D. P., Birkmann, J., Kok, K., Levy, M., and Solecki, W.: The roads ahead: Narratives for shared socioeconomic pathways describing world futures in the 21st century, Global Environ. Chang., doi:10.1016/j.gloenvcha.2015.01.004, online first, 2015.

Pincus, R., Forster, P. M., and Stevens, B.: The Radiative Forcing Model Intercomparison Project (RFMIP): Experimental Protocol for CMIP6, Geosci. Model Dev. Discuss., doi:10.5194/gmd2016-88, in review, 2016.

Popp, A., Calvin, K., Fujimori, S., Humpenöder, F., Stehfest, E., Bodirsky, B., Dietrich, J. P., Doelmann, J., Gusti, M., Hasegawa, T., Kyle, P., Obersteiner, M., Tabeau, A., Takahashi, K., Valin, H., Waldhoff, S., Weindl, I., Wise, M., Kriegler, E., Lotze-Campen, H., Fricko, O., Riahi, K., and van Vuuren, D. P.: Land use futures in the Shared Socio-Economic Pathways, Global Environ. Chang., accepted, 2016.

Riahi, K., Kriegler, E., Johnson, N., Bertram, C., den Elzen, M., Eom, J., Schaeffer, M., Edmonds, J., Isaac, M., Krey, V., Longden, T., Luderer, G., Méjean, A., McCollum, D. L., Mima, S., Turton, H., van Vuuren, D. P., Wada, K., Bosetti, V., Capros, P., Criqui, P., Hamdi-Cherif, M., Kainuma, M., and Edenhofer, O.: Locked into Copenhagen pledges - Implications of short-term emission targets for the cost and feasibility of long-term climate goals, Technol. Forecast. Soc., 90, 8-23, 2015.

Riahi, K., van Vuuren, D. P., Kriegler, E., Edmonds, J., O’Neill, B. C., Fujimori, S., Bauer, N., Calvin, K., Dellink, R., Fricko, O., Lutz, W., Popp, A., Crespo Cuaresma, J., KC, S., Leimbach, M., Jiang, L., Kram, T., Rao, S., Emmerling, J., Ebi, K., Hasegawa, T., Havlik, P., Humpenöder, F., Aleluia Da Silva, L., Smith, S., Stehfest, E., Bosetti, V., Eom, J., Gernaat, D., Masui, T., Rogelj, J., Strefler, J., Drouet, L., Krey, V., Luderer, G., Harmsen, M., Takahashi, K., Baumstark, L., Doelman, J., Kainuma, M., Klimont, Z., Marangoni, G., Lotze-Campen, H., Obersteiner, M., Tabeau, A., and Tavoni, M.: The Shared Socioeconomic Pathways and their energy, land use, and greenhouse gas emissions implications: An Overview, Global Environ. Chang., doi:10.1016/j.gloenvcha.2016.05.009, online first, 2016.

Rogelj, J., Luderer, G., Pietzcker, R. C., Kriegler, E., Schaeffer, M., Krey, V., and Riahi, K.: Energy system transformations for limiting end-of-century warming to below $1.5^{\circ} \mathrm{C}$, Nature Climate Change, 5, 519-527, doi:10.1038/nclimate2572, 2015.

Ruane, A. C., Teichmann, C., Arnell, N., Carter, T. R., Ebi, K. L., Frieler, K., Goodess, C. M., Hewitson, B., Horton, R., Kovats, R. S., Lotze, H. K., Mearns, L. O., Navarra, A., Ojima, D. S., Riahi, K., Rosenzweig, C., Themessl, M., and Vincent, K.: The 
Vulnerability, Impacts, Adaptation, and Climate Services (VIACS) Advisory Board for CMIP6, Geosci. Model Dev. Discuss., doi:10.5194/gmd-2016-71, in review, 2016.

Sherwood, S. C., Bony, S., and Dufresne, J. L.: Spread in model climate sensitivity traced to atmospheric convective mixing, Nature, 505, 37-42, 2014.

Taylor, K. E., Stouffer, R. J., and Meehl, G. A.: An overview of CMIP5 and the experiment design, B. Am. Meteorol. Soc., 93, 485-498, doi:10.1175/BAMS-D-11-00094.1, 2012.

Tebaldi, C. and Arblaster, J. M.: Pattern scaling: its strengths and limitations and an update on the latest model simulations, Climatic Change, 122, 459-471, 2014.

Tebaldi, C., O'Neill, B. C., and Lamarque, J.-F.: Sensitivity of regional climate to global temperature and forcing, Environ. Res. Lett., 10, 074001, doi:10.1088/1748-9326/10/7/074001, 2015.

UNFCCC 2015 Paris Agreements: Durban Platform for Enhanced Action (decision 1/CP.17) Adoption of a protocol, another legal instrument, or an agreed outcome with legal force under the Convention applicable to all Parties, 2015.

van Vuuren, D. P., Edmonds, J., Thomson, A., Riahi, K., Kainuma, M., Matsui, T., Hurtt, G. C., Lamarque, J.-F., Meinshausen, M., Smith, S., Granier, C., Rose, S. K., and Hibbard, K. A.: The Representative Concentration Pathways: an overview, Climatic Change, 109, 5-31, 2011a. van Vuuren, D.P., Edmonds, J., Kainuma, M., Riahi, K., and Weyant, J.: A special issue on the RCPs, Climatic Change, 109, 1-4, doi:10.1007/s10584-011-0157-y, 2011b.

van Vuuren, D. P., Riahi, K., Moss, R., Edmonds, J., Thomson, A., Nakicenovic, N., Kram, T., Berkhout, F., Swart, R., Janetos, A., Rose, S. K., and Arnell, N.: A proposal for a new scenario framework to support research and assessment in different climate research communities, Global Environ. Chang., 22, 21-35, 2012.

van Vuuren, D. P., Kriegler, E., O’Neill, B. C., Ebi, K. L., Riahi, K., Carter, T. R., Edmonds, J., Hallegatte, S., Kram, T., Mathur, R., and Winkler, H.: A new scenario framework for climate change research: scenario matrix architecture, Climatic Change, 122, 373-86, 2014.

Wenzel, S., Cox, P. M., Eyring, V., and Friedlingstein, P.: Emergent constraints on climate-carbon cycle feedbacks in the CMIP5 Earth system models, J. Geophys. Res.-Biogeo., 119, 2013JG002591, doi:10.1002/2013JG002591, 2014.

Wenzel, S., Eyring, V., Gerber, E. P., and Karpechko, A. Y.: Constraining Future Summer Austral Jet Stream Positions in the CMIP5 Ensemble by Process-Oriented Multiple Diagnostic Regression, J. Climate, 29, 673-687, doi:10.1175/JCLI-D-150412.1, 2016. 